\title{
Mapping experience research across disciplines: who, where, when
}

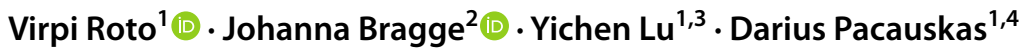

Received: 19 February 2021 / Published online: 17 September 2021

(c) The Author(s) 2021

\begin{abstract}
Human experiences have been studied in multiple disciplines, Human-Computer Interaction (HCI) being one of the largest research fields with its user experience (UX) research. Currently, there is little interaction between experience researchers from different disciplines, although cross-disciplinary knowledge sharing has the potential to accelerate the development of UX and other experience research fields to the next level. This article reports a research profiling study of almost 52,000 experience publications over 125 years, showing the breadth of experience research across disciplines. The data analysis reveals the disciplines that study experiences, the prominent authors, institutions and countries in experience research, the most cited works by experience researchers across disciplines, and how UX research is situated on the map of experience research. This descriptive research profiling study is a necessary first step on the journey of mapping the landscape of experience research, guiding researchers towards understanding experience as a multidisciplinary concept, and establishing a more coherent experience research field.
\end{abstract}

Keywords Experience research $\cdot$ Research profiling $\cdot$ Bibliometric analysis $\cdot$ User experience $\cdot$ Human-computer interaction

\section{Introduction}

The field of Human-Computer Interaction $(H C I)$ has been growing from the first wave of human factors engineering to the second wave of usability and user-friendliness [3]. User experience (UX) is an important keyword of the third wave of $H C I$ [5]. The concept of user experience originates from the industry, and the first academic mention of the term appeared in 1995 [34]. There was quickly raising interest in

Virpi Roto

virpi.roto@aalto.fi

Johanna Bragge

johanna.bragge@aalto.fi

Yichen Lu

yichen.lu@jiangnan.edu.cn

Darius Pacauskas

darius.pacauskas@autovistagroup.com

1 Aalto University School of Arts, Design and Architecture, Espoo, Finland

2 Aalto University School of Business, Espoo, Finland

3 Jiangnan University, Wuxi, China

4 Autovista Group, Helsinki, Finland user experience in industry, but since the new concept was not scientifically grounded, the academia provided several frameworks of user experience [16, 26]. In these early UX works, the citations to experience literature were pointing to cognitive science [8], psychology and philosophy [13, 14], economics [38], and anthropology [48].

Today, we are entering a post-materialistic world, where people are investing in experiences rather than in material possessions. Experiences are increasingly important, and due to the increasing role of interactive technologies in these experiences, UX research is in the key position to provide the needed knowledge on the relation between interactive systems and experiences. $H C I$ is multidisciplinary in its nature, and also UX researchers cite works from the other fields studying experiences. However, understanding the breadth of experience research across disciplines requires systematic investigation. We should start by asking what are the disciplines and research fields that study experiences, and how are they connected? What are the seminal works on human experience? Where does experience knowledge reside, and who are the key experts in this field?

Previous research has reported few reviews of experiencerelated literature across disciplines. Gómez-Corona and Valentin [19] conducted a non-systematic literature analysis of 
user, product, drinking, and eating experiences. While the selected four experiences cover different disciplines, the authors focused their review on consumer research literature. They conclude, as the consumption society will focus more and more on emotions and meanings, the concept of experience should evolve more specific in addressing the physical characteristics, interaction, and consumption of different types of products [19]. Reber [43] studied the experience of art from two different disciplinary perspectives: psychology and art theory. He discussed the roles of art theory and empirical psychology in understanding a work of art in its experience, and how they could interact when examining the work's artistic value [43]. The closest review to our multidisciplinary experience research analysis comes from Ives et al. [24], who reviewed the literature around the multidisciplinary area of Human-Nature Connection. They found that experience-focused research in this area comes primarily from social sciences. We do not know which disciplines study experiences outside Human-Nature Connection. While Ives et al. [24] revealed where Human-Nature Connection experience has been studied, our review focuses on any kind of experiences and covers a much broader spectrum of disciplines.

Studying the experience literature across disciplines helps us to better understand the position of user experience research on the map of experience-related sciences, to identify relevant works, to learn from human experiences, to adopt existing research methods and measures to study human experiences, and thus, to accelerate the maturing of UX research. The urge to reveal the big picture of experience research made us to tackle the laborious task of mapping experience research across all disciplines.

This article reports the results of the endeavor of mapping experience research across disciplines. Research profiling was chosen as the method, since it can extend the span of science by linking efforts across research domains [41]. It can answer our questions on how the volumes of experience research have developed, which disciplines study experiences, where the experience research hubs are located, who are the most active or influential experience researchers, which publications are the most cited by experience researchers, and how are the experience research fields linked. Since our special interest area is $\mathrm{HCI}$, we also study how $\mathrm{HCI}$ field is situated in the map of experience research. The research profiling of more than 50,000 publications from Elsevier's Scopus database with 'experience' or 'experiential' appearing in author keywords provides at least partial answers to the questions we raise above. After explaining the process of extracting the relevant information of the experience publications from Scopus database and the strenuous cleaning process of the extracted data, we present the analysis results using several tables and science visualizations, following the research profiling method's established practices. The discussion section will answer our original questions, elaborate on the limitations of this study, and propose future work in this area.

\section{Materials and methods}

The research method in this study followed the research profiling process presented by Porter et al. [41]. Research profiling is empowered by advanced text-mining tools combined with modern search engines and science databases (ibid.). Especially the Web of Science, Scopus and Google Scholar are deployed in these broad bibliometric studies [22]. Textmining tools enable deriving novel information, such as patterns, associations and trends from the text data [12], and they are becoming increasingly common in large-scale literature analyses. Tools and analyses that can be applied in these studies are portrayed and compared e.g. in Cobo et al. [10] and Chen [9]. The research profiling method has been applied previously in numerous bibliometric studies regarding various topics such as personalization and masscustomization [47], behavioral pricing [46], green supply chain management [44], and new product development [35]. The amounts of bibliometric data that are analyzed vary typically from a couple of hundreds to several thousands. Examples of other massive-scale analyses are the studies by Rafols et al. [42], who portray a global map of science using all research published in 2007 as indexed in the Web of Science, and Bragge et al. [6], who profile all research related to multiple-criteria decision making.

The research profiling process [41] starts with the initializing phase of topic identification, selection of information sources, search refinement and data retrieval, and data cleaning. After that, basic tabular and more advanced visual analyses utilizing various text-mining and visualization tools are conducted. Based on the purpose of the research, the most relevant analyses are selected for representation and interpretation.

The main challenge in locating experience-focused research is the term 'experience', which is a commonly used word in articles that are not actually studying experience, e.g., "Previous experience shows..." or "... both newcomers and experienced scientists". Word 'experience' appears in the title, abstract or keywords of more than 1.8 million publications indexed in the Scopus database. Checking the relevance of 30 abstracts of the publications in this vast sample revealed that only 9 of them were about experience research. When the search was narrowed down to author keywords only, it dramatically improved the relevance of the retrieved publications. While it is impossible to identify and include all publications of experience research in a bibliometric analysis, we are still able to reveal major parts of the 
scientific landscape by studying the literature with 'experience' or 'experiential' mentioned as an author keyword.

We selected the Scopus citation database as our main information source, as it provided us with the most comprehensive set of results related to experience research, in total 52,307 publications, restricting the results from the first appearance in 1894 to the latest full year of 2018. We then exported the full bibliographic records of the search results, including cited references, in CSV format in March 2019. We discarded notes, errata and letters to the editor, and kept only the following document types for further inspection: articles, articles in press, conference papers, book chapters, books and reviews. This left us with 51,901 publications.

In our multi-disciplinary research focus, we were especially interested in retrieving the subject area data, which reveals the disciplinary areas of each publication source. Unfortunately, the standard Scopus interface did not provide the subject area data in the exported results, although they could be seen at the aggregate level when inspecting the results through the search interface. Thus, we utilized the application programming interface (API) of Scopus and complemented our data set with this data and also other relevant fields that were available only via the API, such as the author ID's. Author ID's were necessary to combat the homonyms in the names, especially regarding similar Asian names such as "Wang, Y." (see [20, 21]). Regarding the subject categories, all publication titles such as journals and conference proceedings in Scopus are classified using the All Science Journal Classification (ASJC) scheme. The three-level classification is done by Scopus experts and it is based on the aims and scope of the publication venue, and on the content it publishes. ${ }^{1}$ Thus, it is not based on individual article level.

The four top level ASJC categories, called "subject areas", are Health Sciences, Life Sciences, Physical Sciences, and Social Sciences and Humanities. For example, the Physical Sciences subject area is further categorized into mid-level ASJC "classes" Chemical Engineering; Chemistry; Computer Science; Earth and Planetary Sciences; Energy; Engineering; Environmental Science, Material Science; Mathematics; Physics and Astronomy; and Multidisciplinary. These mid-level classes are further divided into 334 "fields", e.g., Computer Science covers 13 fields, such as Human-Computer Interaction, Artificial Intelligence, and Information Systems, which are shown in italics in this article. In addition to the term field, in this article we also use the terms research field or discipline as synonyms to the lowest level categories in the ASJC hierarchy. A single publication may be categorized under several fields or mid

\footnotetext{
1 https://service.elsevier.com/app/answers/detail/a_id/14882/suppo rthub/scopus, retrieved October 21, 2019.
}

classes or even top level subject areas at the same time. The ASJC data was missing from $0.7 \%$ (363) of the publications.

After exporting the data from Scopus, we imported them to VantagePoint, which is a proprietary text-mining tool by Search Technology Inc. designed for science and patent data [40]. VantagePoint caters a versatile set of statistical and Natural Language Processing (NLP) tools for text-based data, and it is also particularly useful in the laborious data cleaning phase, where it can provide the analyst suggestions for terms to be combined using fuzzy logic techniques. For example, author names can be written in slightly different ways, or the terms used in keyword fields, titles and abstracts contain synonyms that should be combined (singular vs. plural forms, full names vs. abbreviations, English vs. American spelling, etc.). With the large data set of almost 52,000 records, the cleaning of the data took a considerable amount of time (several days for each field to be cleaned), as the suggestions made by the tool needed to be confirmed by a human analyst. It is typical in big data projects that the cleaning phase takes $80-90 \%$ of time [25], and this was the case in our study as well.

After the cleaning phase, we conducted several bibliometric analyses to the data: productivity analyses (such as the most prolific countries, institutions and authors), temporal analyses depicting the evolution and trends of experience research, and cartographic science mapping algorithms to uncover hidden patterns in the data (such as scholarly networks based on co-authorship relation, co-word occurrence of keywords, or co-citation of cited sources or cited authors). In this phase, we deployed a visualization of similarities software called VOSviewer [49]. It is a continuously developed and free scientometric tool that has been applied in thousands of scholarly journal publications to date.

\section{Results}

Our data set covers all publications indexed by Scopus that mention experience or experiential in the author keywords field, and the first such publications have appeared already at the 1890's. The first publication in our data set is Fullerton's [17] article on "The psychological standpoint", published in Psychological Review. The following sections report the results of the publication volumes, disciplines, research hubs, prolific authors and most cited publications of experience research across the Scopus research fields. The last section maps the links between the disciplines.

\section{Volumes of experience publications}

Our bibliometric analysis covers 125 years from 1894 to 2018 and includes 51,901 publications with 'experience' or 'experiential' in the author keywords field. Almost 69\% 
Fig. 1 Trend in publication amounts per decennium (note that the last decennium is 9 years instead of 10 due to the time of exporting the data in early 2019)

Fig. 2 Annual numbers of experience publications in this millennium
Amount of experience research per decennium and in total

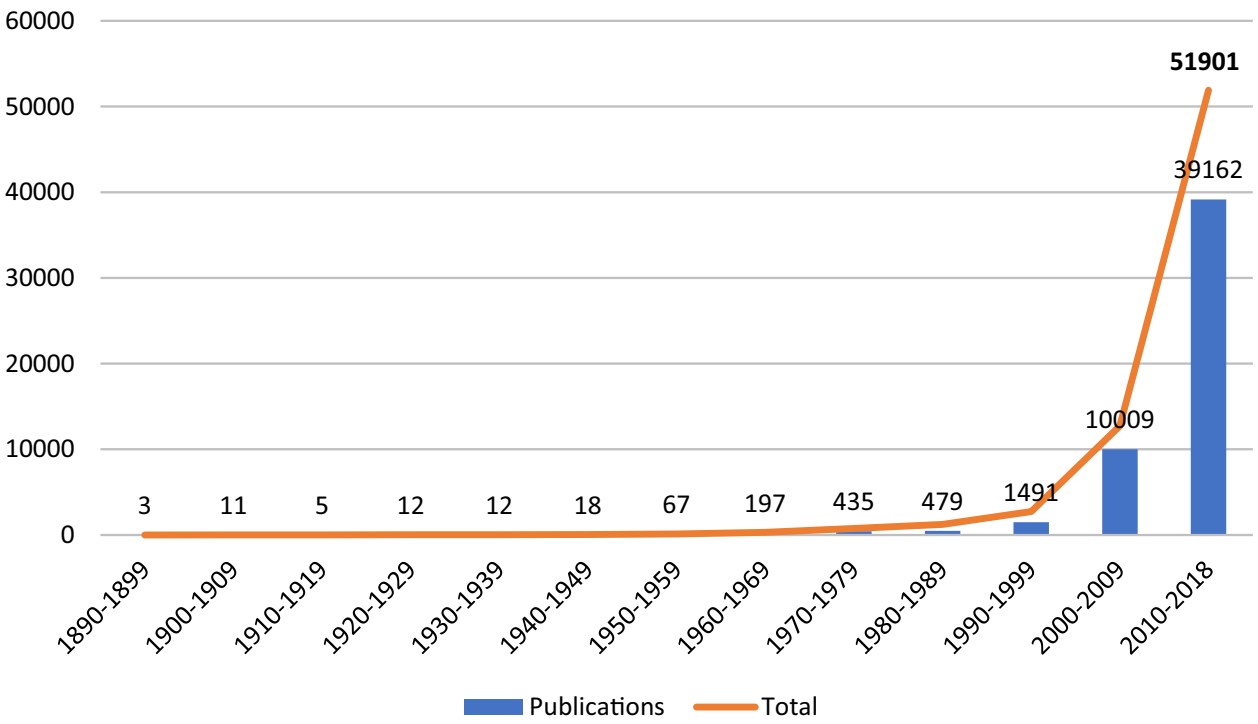

Number of experience publications during years 2000-2018

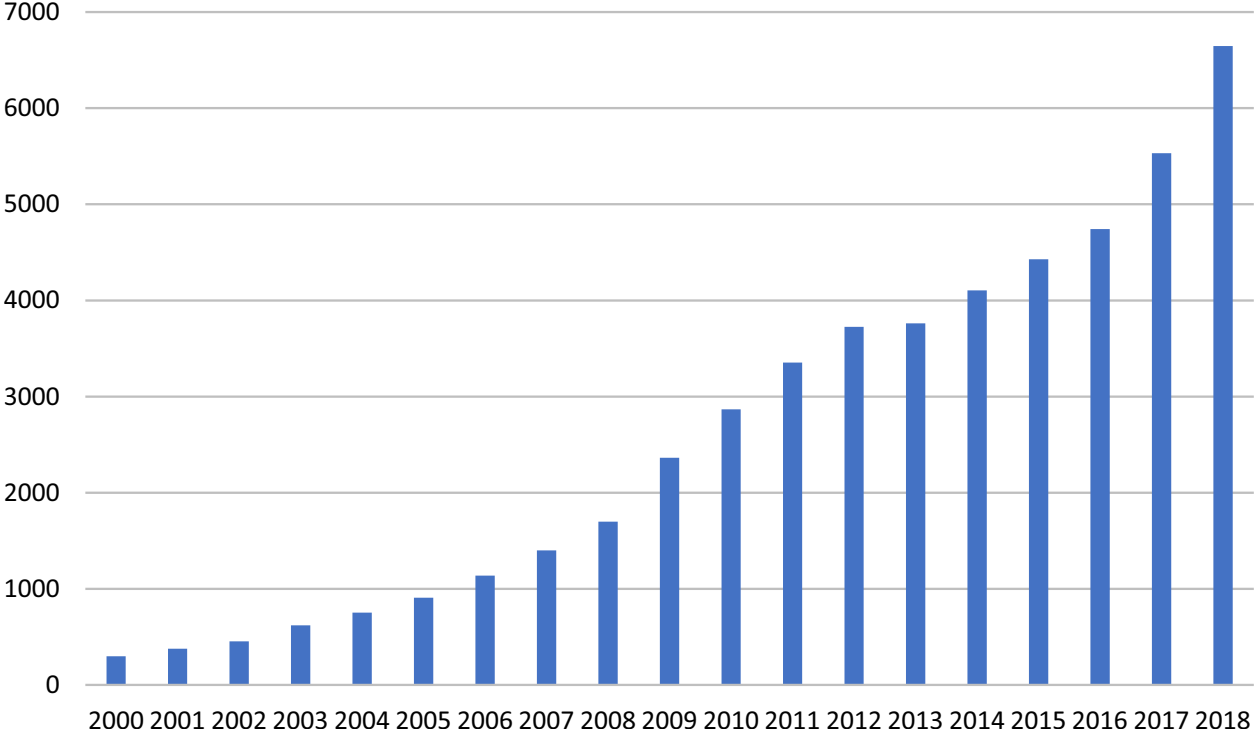

of the publications are articles (or articles in press), 21.4\% conference proceeding papers, $5.3 \%$ book chapters or books, and $4.6 \%$ reviews. The analysis reveals that $80 \%(41,525)$ of the experience publications have appeared during the latest ten years (2009-2018), and almost 50\% $(25,454)$ have come out during the last 5 years (2014-2018). The two latest years account for $23.5 \%$ of the publications. The accelerating growth of experience research is depicted in Fig. 1.

The annual publication numbers in this millennium (Fig. 2) show that the volume of experience publications has been growing each year with notable increments in years 2009 (39.1\%), 2017 (16.6\%) and 2018 (20.1\%). The recent development may indicate an increasing pace of growth for experience publications.

Figure 3 depicts the growth of the 17 most popular experience research fields in 2010-2018. Although Education and Psychiatry and Mental Health are old fields in experience research, they still keep growing in experience publication volumes. The obvious experience research domain of Tourism, Leisure and Hospitality Management has clearly grown in volumes during the last years. New growth can be seen also in Public Health, Environmental and Occupational Health and in Strategy and Management fields. After a rapid growth during the first decade of this 


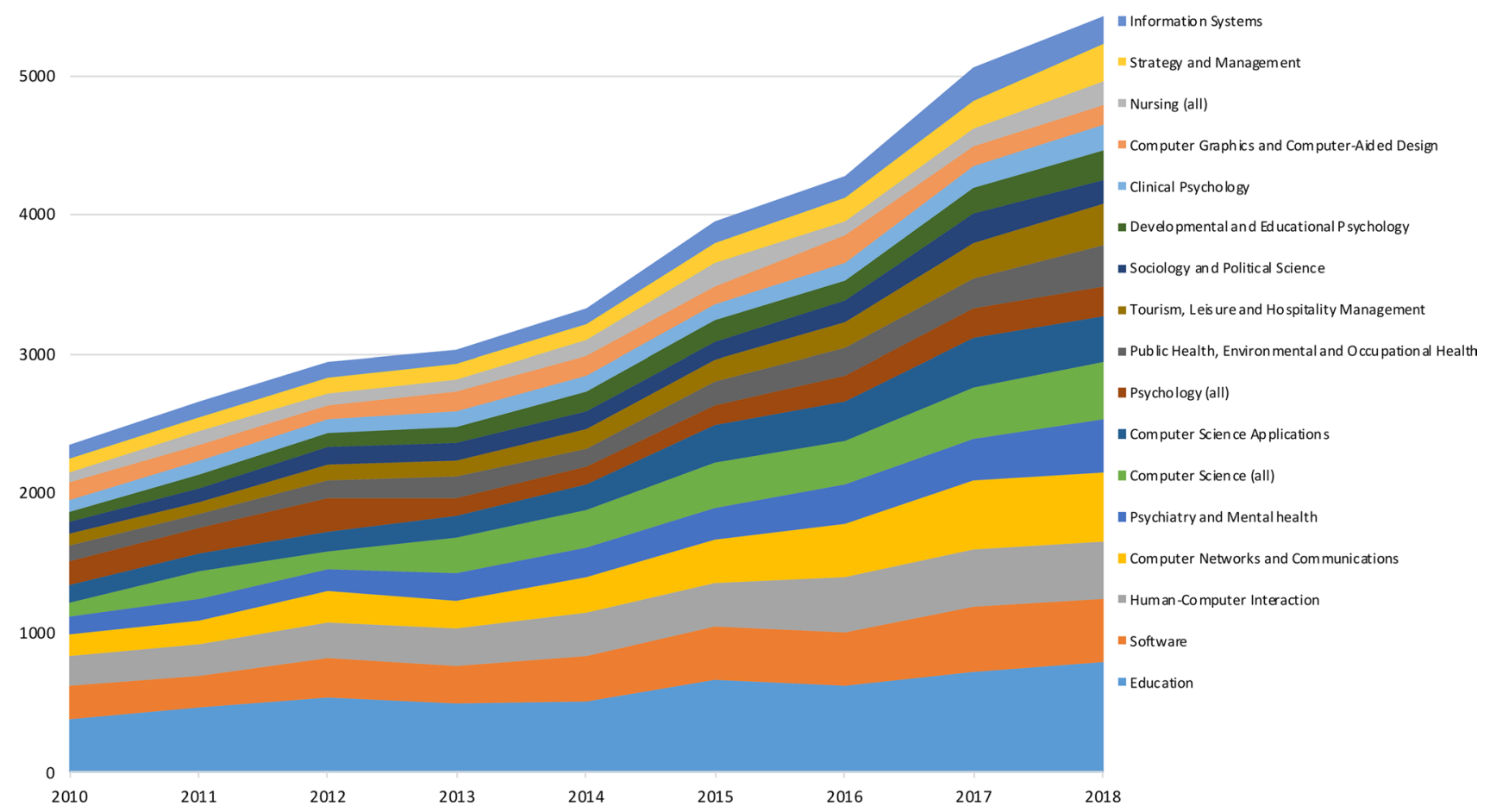

Fig. 3 Annual publication numbers in 2010-2018 for the 17 largest research fields (ASJC low)

millennium, $H C I$ volumes have been stable with a bit more than 400 publications annually during years 2016-2018, while the Computer Networks and Communications field is growing. The rapid growth of all experience publications in years 2017 and 2018 is not explained by any specific topic area, but the growth trend seems to be common across the ASJC fields. Similar trends may be influenced by the fact that one publication venue is often categorized under several ASJC fields, and its growth influences all those fields.

\section{Disciplines studying experiences}

In our data set, a little over half of the publications are categorized under Social Sciences and Humanities, a third under Physical Sciences, 28\% under Health Sciences, $10 \%$ under Life Sciences, and a small amount $(0.3 \%)$ under the General category (see Fig. 4). This distribution of experience publications is in line with Ives et al. [24], whose literature analysis found human-nature experience publications primarily from Social Sciences and Humanities, but also from Physical and Health Sciences. Our much broader data set covers Life Sciences as well (Fig. 4).

The beginning of experience research was dominated by Psychology. Out of 325 experience publications up to year 1969, 315 were from Psychology journals (20 different ones). The 10 others were published in Medicine. Starting from year 1970, the spectrum of experience research started to slowly widen with respect to scientific fields, however, Psychology and Medicine still dominated the experience research arena for quite a while.

The first two articles categorized under Human-Computer Interaction appeared in 1994 and listed 'experience' and 'domain experience' as keywords. Less than $6 \mathrm{HCI}$ articles with experience or experiential as a keyword were published annually until year 2001, after which the amounts started to take off fast, with over 400 articles published annually for years 2016-2018.

Almost all research fields have contributed to experience research, since they cover 326 out of all 334 ASJC research fields. However, the most active experience fields are easy to identify, since the ten most prolific fields account for almost half of the research $(48 \%)$, as can be seen from Table 1 . The twenty largest fields appear in $61.4 \%$ of the publications. Of all research fields, Education is clearly leading experience research in numbers, with $12.8 \%$ of the experience publications categorized to this field. Software comes next with $7.6 \%$ share. While $\mathrm{HCI}$ is a relatively young research field, in this data sample 
Fig. 4 Major subject areas of the publications (note that one publication may belong to two areas)
Major subject areas of the publications

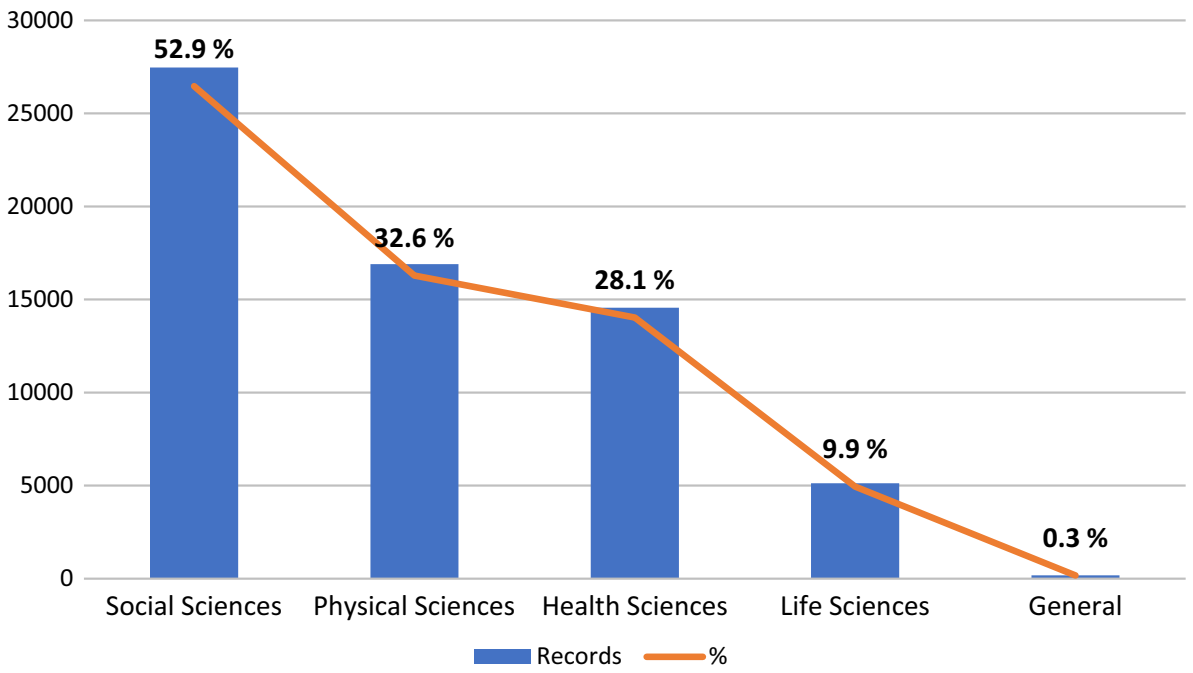

covering 125 years it is the third most active field publishing experience research, accounting for $6.6 \%$ of all experience publications. Its share increases to $7.2 \%$ when examining the last five years only. $\mathrm{HCI}$ may be the reason behind the frequency of the five Computer Science fields among the top ten fields in Table 1, since the HCI publication venues are often categorized not only under $\mathrm{HCI}$ but also under other fields of Computer Science. The reason behind Education leading this list may be due to its general nature and its connection to every research field (e.g., nursing education, computer science education). There are specialized education journals in several research fields, and it is also included as an auxiliary topic in general journals. Therefore, the number of venues categorized as Education grows high, and so does the number of experience publications in these venues.

A different view to the disciplines studying experiences can be seen in the most popular publication venues in Table 2. Three Computer Science-related proceedings series lead the list, followed by five health, nursing, pharmaceutics, and psychology-related venues. There are two educationrelated venues on the top ten list of experience venues. Lecture Notes in Computer Science is a clear leader with 1464 experience publications. This Springer series publishes conference proceedings, with around 22,000 conference papers annually, which is difficult for the other publication venues to compete with. The next two publication venues are ACM International Conference Proceeding Series with 653 publications and $\mathrm{CHI}$ conference proceedings with 643 publications. Although the publication venues of Computer Science are leading the list in Table 2, it only communicates this discipline collects more publications under one publication venue than the other disciplines. Still, it is interesting to see which publication venues are popular in different disciplines.

\section{Experience research hubs}

Table 3 and Fig. 5 portray the country level statistics of our data sample for the top 20 most prolific countries in experience research. The countries representing the Western cultures, USA, UK, Australia, Canada, and Germany dominate this list. Out of the top 20 countries, 12 are in Europe and five in Asia. An analysis of the research fields of experience research in these 20 countries (Table 4) reveals interesting differences, as the top three ASJC fields on a global scale (Education, Software and $H C I$ ) are the top 3 experience research areas in Denmark only. Education is the clearly dominating experience research field in the top 4 countries (USA, UK, Australia and Canada). In the USA, Psychologyrelated areas take five out of the top ten experience research areas, and $\mathrm{HCI}$ is the 8th area only. In UK, health topics take three of the top 6 areas. The top 3 topics also reveal special experience research strengths of some countries, such as Tourism in Australia and Norway, and Marketing in India. In Sweden, experience research is largely related to health, also in rare fields such as Obstetrics and Gynaecology, Health Policy, and Maternity and Midwifery. In China, the top 3 topics are related to computing. In Denmark and Finland, $\mathrm{HCI}$ is the most popular field of experience research and $\mathrm{HCI}$ is within the top 3 experience research areas also in Germany, Netherlands, South Korea, Switzerland, UK, France, and Belgium. The top Asian countries (China, South Korea, Japan, and India) except Taiwan study experiences in Electrical and Electronic Engineering, while health-related topics are missing from the top ten experience research fields in these countries. In all top 20 countries, $H C I$ is within the top ten experience research fields (Table 4).

If focusing on the numbers of $H C I$ publications per country, the top two countries publishing experience 


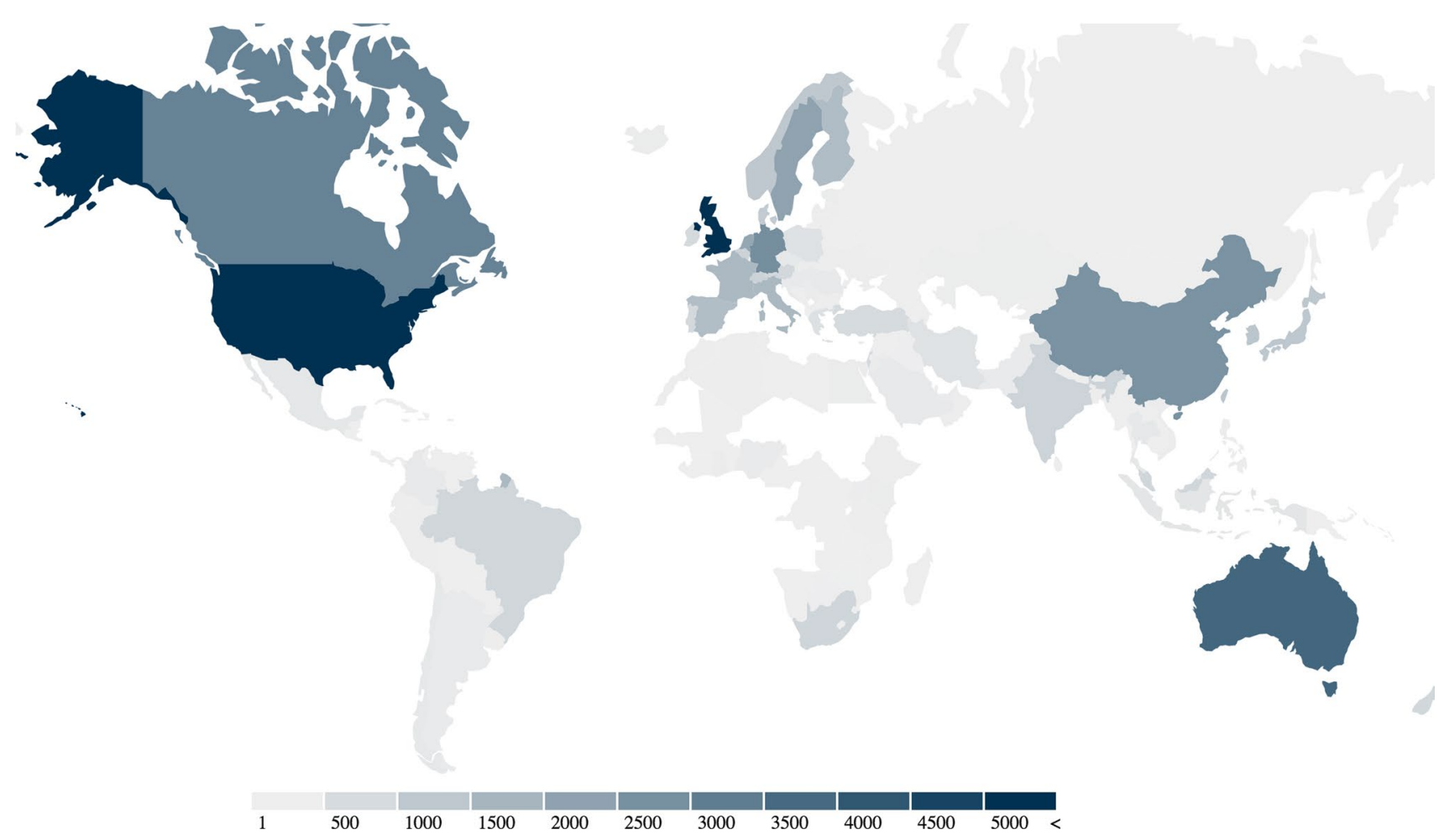

Fig. 5 Amount of experience publications per country

research in $H C I$ publication venues are the same, USA and UK (Table 5). However, Finland, Germany, and the Netherlands appear on top of the list together with Australia and Canada. The popularity of UX research among Finnish experience researchers makes Finland climb from position 11 to position 3 in the $H C I$ list.

Looking at experience publications per million inhabitants provides per capita view to productivity of the nation in publishing experience research. Through this lens, Finland with $5.5 \mathrm{M}$ inhabitants stands out as the most productive country in publishing experience research in $\mathrm{HCI}$ venues, followed by Denmark, Austria, Ireland, Sweden, and the Netherlands.

The most productive institutions in experience publications are listed in Table 6 . While USA as a country is number one in the volumes of experience publications, the research seems to be scattered in different universities. The first US university appears on the 16th position, after four universities from UK and four from Australia.

Only $9 \%$ of experience publications coming from the USA originate from the universities listed in Table 6 , while for Australia, the universities on this list cover $56 \%$ of the Australian experience publications. Especially in Sweden, the experience researchers seem to sit in the six universities listed in Table 6, since they cover $66 \%$ of all Swedish experience publications. In Belgium, more than a third of experience publications come from KU
Leuven, and almost a fourth from Universiteit Gent (Ghent University).

Table 7 depicting the most productive institutions publishing experience research in $\mathrm{HCI}$ venues completes our analysis of experience research hubs. Finland leads the list with 4 universities among the top ten institutions, and also Nokia has its main operations in Finland. Tampere University of Technology is the only institution with more than a hundred HCI publications. Compared to the list of institutions with more than 150 experience publications, the institutions are largely different for $\mathrm{HCI}$ focus (aside from Finland). For example, Universitat Salzburg is ranked 5th on the $\mathrm{HCI}$ list, but not visible among experience research hubs presented in Table 6 . A remarkable difference between $\mathrm{HCI}$ and the general experience research is the appearance of three corporations on the $H C I$ list: Nokia, Google, and Microsoft.

\section{Prominent authors of experience research}

Table 8 lists the authors having at least 20 publications with 'experience' or 'experiential' as the author keywords. The most productive authors in this experience research group are Manfred Tscheligi (74 publications, University of Salzburg), Jim van Os (66, multiple affiliations in Maastricht, Utrecht, and London), and Kaisa Väänänen-Vainio-Mattila (62, Tampere University of Technology). When we rank the 
Table 1 Research fields with more than 1000 experience publications

\begin{tabular}{|c|c|c|c|}
\hline Rank & Field (ASJC) & Publications & $\%$ \\
\hline 1 & Education & 6663 & 12.8 \\
\hline 2 & Software & 3925 & 7.6 \\
\hline 3 & Human-Computer Interaction & 3443 & 6.6 \\
\hline 4 & Computer Networks and Communications & 3067 & 5.9 \\
\hline 5 & Psychiatry and Mental health & 2964 & 5.7 \\
\hline 6 & Computer Science (all) & 2698 & 5.2 \\
\hline 7 & Computer Science Applications & 2612 & 5.0 \\
\hline 8 & Psychology (all) & 2165 & 4.2 \\
\hline 9 & Public Health, Environmental and Occupational Health & 1995 & 3.8 \\
\hline 10 & Tourism, Leisure and Hospitality Management & 1842 & 3.5 \\
\hline 11 & Sociology and Political Science & 1805 & 3.5 \\
\hline 12 & Developmental and Educational Psychology & 1707 & 3.3 \\
\hline 13 & Clinical Psychology & 1678 & 3.2 \\
\hline 14 & Computer Graphics and Computer-Aided Design & 1627 & 3.1 \\
\hline 15 & Nursing (all) & 1619 & 3.1 \\
\hline 16 & Strategy and Management & 1585 & 3.1 \\
\hline 17 & Information Systems & 1584 & 3.1 \\
\hline 18 & Theoretical Computer Science & 1584 & 3.1 \\
\hline 19 & Social Psychology & 1403 & 2.7 \\
\hline 20 & Marketing & 1385 & 2.7 \\
\hline 21 & Medicine (all) & 1385 & 2.7 \\
\hline 22 & Business and International Management & 1365 & 2.6 \\
\hline 23 & Electrical and Electronic Engineering & 1336 & 2.6 \\
\hline 24 & Engineering (all) & 1294 & 2.5 \\
\hline 25 & Arts and Humanities (miscellaneous) & 1285 & 2.5 \\
\hline 26 & Applied Psychology & 1211 & 2.3 \\
\hline 27 & Social Sciences (all) & 1189 & 2.3 \\
\hline 28 & Geography, Planning and Development & 1175 & 2.3 \\
\hline 29 & Arts and Humanities (all) & 1162 & 2.2 \\
\hline 30 & Health (social science) & 1077 & 2.1 \\
\hline 31 & Computer Vision and Pattern Recognition & 1068 & 2.1 \\
\hline 32 & Experimental and Cognitive Psychology & 1003 & 1.9 \\
\hline
\end{tabular}

authors by their h-index in experience research, calculated from the citations across the publications in our sample, the top three list is Jim van Os (h-index 26), Paul J. Silvia (19, University of North Carolina at Greensboro), and Inez MyinGermeys (18, KU Leuven). They all publish in Medicine and Psychology, more specifically in Psychiatry and Mental health, and in Developmental and Educational Psychology. Myin-Germeys has co-authored several publications both with van Os (134) and Silvia (6), which indicates the top 3 authors are working on similar topics.

Approximately a third of the most productive authors of all times in experience research publish in $\mathrm{HCI}$ venues (Table 8). The top 3 HCI authors based on the number of experience publications are Manfred Tscheligi (74 publications), Kaisa Väänänen-Vainio-Mattila (62) and Marc Hassenzahl (49). The top HCI authors are slightly different if we rank them by the h-index within our sample articles: Marc Hassenzahl (h-index 18) and Kaisa VäänänenVainio-Mattila (16) are followed by Lennart Nacke (13) and Virpi Roto (13).

When looking at all 1.2 million references in the 51,901 experience publications, the most cited authors expand beyond the ones who authored the publications in our data set (Table 9). Since more than a million references in our sample could not be fully cleaned, we manually checked that each author in Table 9 was a unique one in Scopus. Five Asian name homonyms were removed from the top authors list, since more than 10 individual authors were behind names Kim, J., Wang Y, Liu Y, Lee, Y., and Lee, $\mathrm{S}$. While the preparation for the analysis of references was laborious, it provides an interesting perspective to a wider set of authors and works relevant for experience research. 
Table 2 The most popular journal and conference venues for experience research

\begin{tabular}{|c|c|c|c|}
\hline Rank & Source title Full name & $\begin{array}{l}\text { Records in journal } \\
\text { venues }\end{array}$ & $\begin{array}{l}\text { Records in } \\
\text { conference } \\
\text { venues }\end{array}$ \\
\hline 1 & Lecture Notes in Computer Science (incl. LN in AI and LN in Bioinformatics) & & 1464 \\
\hline 2 & ACM International Conference Proceeding Series & & 653 \\
\hline 3 & Conference on Human Factors in Computing Systems_-Proceedings & & 643 \\
\hline 4 & Qualitative Health Research & 302 & \\
\hline 5 & Journal of Clinical Nursing & 289 & \\
\hline 6 & American Journal of Pharmaceutical Education & 246 & \\
\hline 7 & Journal of Advanced Nursing & 216 & \\
\hline 8 & Frontiers in Psychology & 195 & \\
\hline 9 & Proceedings-Frontiers in Education Conference, FIE & & 194 \\
\hline 10 & Communications in Computer and Information Science & 177 & \\
\hline 11 & Journal of Comparative and Physiological Psychology & 172 & \\
\hline 12 & Scandinavian Journal of Caring Sciences & 168 & \\
\hline 13 & Advances in Intelligent Systems and Computing & 160 & \\
\hline 14 & Computers in Human Behavior & 153 & \\
\hline 15 & Midwifery & 143 & \\
\hline 16 & Physiology and Behavior & 137 & \\
\hline 17 & Journal of Business Research & 131 & \\
\hline 18 & CEUR Workshop Proceedings & & 130 \\
\hline 19 & Developmental Psychobiology & 129 & \\
\hline 20 & Tourism Management & 125 & \\
\hline 21 & Currents in Pharmacy Teaching and Learning & 120 & \\
\hline 22 & Journal of Personality and Social Psychology & 114 & \\
\hline 23 & Journal of Counseling Psychology & 113 & \\
\hline 24 & Nurse Education Today & 113 & \\
\hline 25 & Social Science and Medicine & 113 & \\
\hline 26 & Personality and Individual Differences & 103 & \\
\hline 27 & Proceedings of SPIE—The International Society for Optical Engineering & & 100 \\
\hline 28 & Journal of Experiential Education & 99 & \\
\hline 29 & Consciousness and Cognition & 98 & \\
\hline 30 & Journal of Management Education & 96 & \\
\hline 31 & Child Abuse and Neglect & 93 & \\
\hline 32 & Psychiatry Research & 91 & \\
\hline 33 & Schizophrenia Research & 89 & \\
\hline 34 & Simulation and Gaming & 89 & \\
\hline 35 & Disability and Rehabilitation & 87 & \\
\hline 36 & Teaching and Teacher Education & 87 & \\
\hline 37 & Annals of Tourism Research & 86 & \\
\hline 38 & International Journal of Qualitative Studies on Health and Well-being & 86 & \\
\hline 39 & European Journal of Cancer Care & 84 & \\
\hline 40 & Higher Education Research and Development & 84 & \\
\hline 41 & Journal of Travel and Tourism Marketing & 84 & \\
\hline 42 & BMC Health Services Research & 81 & \\
\hline 43 & European Journal of Oncology Nursing & 79 & \\
\hline 44 & International Journal of Nursing Studies & 79 & \\
\hline 45 & Journal of Travel Research & 75 & \\
\hline 46 & Cancer Nursing & 72 & \\
\hline 47 & Multimedia Tools and Applications & 72 & \\
\hline
\end{tabular}


Table 3 Top 20 countries in experience research

\begin{tabular}{llrrrrrrrrrr}
\hline & Country & TP & TC & h-ix & TC/TP & HiCP & $>1000$ & $>500$ & $>250$ & $>100$ & $>50$ \\
\hline 1 & USA & 14,861 & 262,415 & 177 & 17.66 & 2132 & 6 & 29 & 113 & 456 & 1195 \\
2 & UK & 7349 & 107,366 & 117 & 14.61 & 947 & 0 & 5 & 28 & 163 & 469 \\
3 & Australia & 3533 & 43,601 & 79 & 12.34 & 420 & 0 & 0 & 3 & 48 & 184 \\
4 & Canada & 2809 & 44,595 & 87 & 15.88 & 1252 & 2 & 2 & 15 & 69 & 185 \\
5 & Germany & 2495 & 31,277 & 70 & 12.54 & 739 & 0 & 1 & 10 & 41 & 127 \\
6 & China & 2411 & 12,230 & 43 & 5.07 & 1150 & 1 & 1 & 1 & 12 & 37 \\
7 & Sweden & 1975 & 30,400 & 66 & 15.39 & 1414 & 1 & 2 & 3 & 28 & 127 \\
8 & Netherlands & 1878 & 35,282 & 84 & 18.79 & 1296 & 1 & 2 & 10 & 67 & 177 \\
9 & Italy & 1399 & 15,172 & 54 & 10.84 & 908 & 0 & 1 & 4 & 16 & 59 \\
10 & France & 1384 & 19,355 & 62 & 13.98 & 1542 & 1 & 2 & 5 & 25 & 90 \\
11 & Finland & 1287 & 16,731 & 58 & 13.00 & 626 & 0 & 1 & 5 & 23 & 68 \\
12 & Spain & 1258 & 13,205 & 53 & 10.50 & 499 & 0 & 0 & 4 & 17 & 54 \\
13 & South Korea & 1069 & 8448 & 41 & 7.90 & 333 & 0 & 0 & 3 & 10 & 29 \\
14 & Taiwan & 1055 & 11,017 & 45 & 10.44 & 989 & 0 & 2 & 3 & 13 & 40 \\
15 & Japan & 1002 & 7016 & 35 & 7.00 & 671 & 0 & 1 & 1 & 3 & 20 \\
16 & Norway & 994 & 13,736 & 56 & 13.82 & 640 & 0 & 1 & 3 & 21 & 61 \\
17 & Denmark & 910 & 11,843 & 53 & 13.01 & 240 & 0 & 0 & 0 & 18 & 56 \\
18 & Switzerland & 708 & 12,726 & 55 & 17.97 & 486 & 0 & 0 & 3 & 24 & 60 \\
19 & Belgium & 696 & 9760 & 46 & 14.02 & 376 & 0 & 0 & 2 & 17 & 42 \\
20 & India & 681 & 2815 & 24 & 4.13 & 130 & 0 & 0 & 0 & 2 & 3 \\
\hline
\end{tabular}

$\mathrm{TP}=$ total experience publications, $\mathrm{TC}=$ total citations to experience publications, $\mathrm{h}$-ix $=\mathrm{h}$-index, $\mathrm{TC} /$ $\mathrm{TP}=$ average citations, $\mathrm{HiC}=$ highest $\mathrm{nr}$. of citations to one publication, $>\mathrm{n}=\mathrm{Nr}$. of publications receiving at least $\mathrm{n}$ citations
The most cited authors by the publications in our data set are Mihaly Csikszentmihalyi (psychologist), David A. Kolb (educational theorist), and Anselm L. Strauss (sociologist). Although $\mathrm{HCI}$ scores high in the quantity of experience publications, among the top 35 cited authors there are only three HCI scholars: Marc Hassenzahl (ranked 6th), Donald Norman (12th), and Jakob Nielsen (30th) (Table 9).

\section{Most cited experience publications}

Next, we complement our review of citation counts by the citations to the experience publications. In this analysis, we count the number of citations from all publications in Scopus to the publications in our data set (i.e., 'Times cited' statistics in Scopus). A large majority, $72 \%$, of the experience publications have earned less than 10 citations (Fig. 6). Almost 27\% of the publications have no citations. Only 17 experience publications have received more than 1000 citations by March 2019, the highest citation count being 2132 (Table 10). Out of the 17, nine publications are categorized in the Psychology subject area class, six in Business, Management and Accounting, and the rest in Decision Sciences (3), Social Sciences (3), Arts and Humanities (2), Computer Science (2), Economics, Econometrics and Finance (2), Medicine (2), Neuroscience (2), and Biochemistry, Genetics and Molecular Biology (1).
The most cited Computer Science articles are published in MIS Quarterly, which is an Information Systems journal. Eight of the 17 most cited articles were published since 2000, and the oldest publication originates from 1974. Naturally, the most cited publications collect citations not only for their experience research content, so we cannot claim that the publications in Table 10 are the most important publications for experience research.

In Table 10, there is only one publication related to Computer Science, and none from HCI. Therefore, it is interesting also to look at the most cited publications in the research fields under the mid-level ASJC category of Computer Science in Table 11. The field of Information Systems takes up the top 3 positions and 5 MIS Quarterly articles appear among the top 20 list. Kristian Kiili's publication on experiential gaming is categorized under Education, Computer Science Applications and Computer Networks and Communications, and it is the most cited Education publication within our whole data set [27]. The top cited HCI publications in Table 11 start from the 13th position with Law et al. [30], followed by Seaborn and Fels [45], Durndell and Haag [15], and Lee and Ma [31]. 


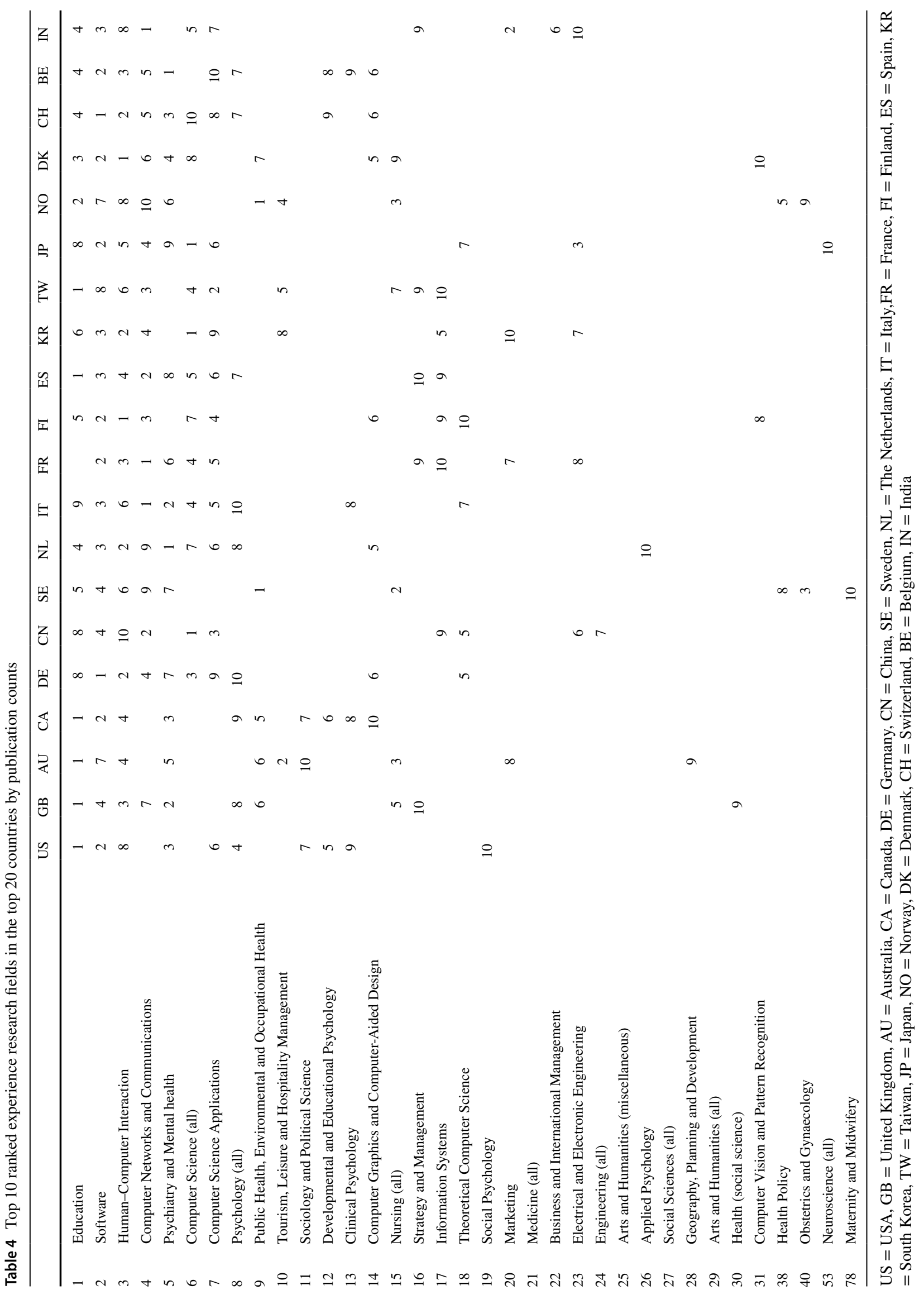


Table 5 The most prolific countries in Human-Computer Interaction area

\begin{tabular}{llrr}
\hline & Country & TP & Per 1 M \\
\hline 1 & United States & 674 & 2.05 \\
2 & United Kingdom & 526 & 7.86 \\
3 & Finland & 331 & 59.52 \\
4 & Germany & 327 & 3.97 \\
5 & Australia & 216 & 8.61 \\
6 & Netherlands & 195 & 11.38 \\
7 & Canada & 176 & 4.72 \\
8 & Austria & 141 & 16.08 \\
9 & Denmark & 126 & 21.82 \\
10 & Sweden & 121 & 12.04 \\
11 & China & 121 & 0.09 \\
12 & Spain & 107 & 2.30 \\
13 & Italy & 102 & 1.72 \\
14 & South Korea & 101 & 1.97 \\
15 & France & 96 & 1.47 \\
16 & Taiwan & 82 & 3.45 \\
17 & Portugal & 80 & 7.80 \\
18 & Japan & 79 & 0.62 \\
19 & Switzerland & 72 & 8.36 \\
20 & Ireland & 64 & 13.20 \\
21 & Malaysia & 59 & 1.82 \\
22 & Belgium & 58 & 5.02 \\
23 & Brazil & 54 & 0.04 \\
24 & Norway & 47 & 0.81 \\
25 & India & 0.19 \\
\hline
\end{tabular}

$\mathrm{TP}=$ total experience publications in $\mathrm{HCI}$, Per1M=Publications per million inhabitants

\section{Links between different disciplines}

We studied the links between disciplines by the references in the publications of each research field. The more overlap between the references, the stronger the link. Figure 7 depicts this "cross-correlation" similarity map of the 50 largest experience research fields. Only the 70 strongest links are shown to avoid clutter in the graph (in total, there are 1225 links as shown in the legend-the number in parentheses shows the number of links not shown). The 50 biggest research fields cover all four top-level Subject Areas of ASJC: Social, Physical, Health, and Life Sciences, and 12 mid-level ASJC classes that are color-coded in Fig. 7. The Physical Sciences (blue labels) are dominated by Computer Science, which includes 10 strongly interlinked fields, Software and $\mathrm{HCI}$ as the largest ones. Three fields from Engineering class are close, but only the general Engineering (all) field is strongly linked to the Computer Science class. Theoretical Computer Science is categorized under Mathematics, and it has four strong links to the Computer Science fields, including HCI. Information Systems and Management, categorized under Decision Sciences, is the only experience research field outside Physical Sciences that is strongly linked to Computer Science. It is interesting that experience research in Artificial Intelligence is quite isolated from the other Computer Science topics.

Similarly to Computer Science, the eight experience research fields under the Business, Management and Accounting class (purple labels) are strongly interconnected, except Tourism, Leisure and Hospitality Management, which is strongly interconnected to Geography, Planning and Development under Social Sciences class.

More Social Sciences \& Humanities (green and dark red labels) can be found in the center of Fig. 7: six fields of Psychology, nine fields of Social Sciences, and three fields of Arts and Humanities. These research fields are not as tightly interconnected as those under Computer Science and Business, Management and Accounting. There are some strong links between five Psychology fields, and a Social Sciences field of Sociology and Political Science has strong links to Social Psychology and Social Sciences (all). Arts and Humanities (Miscellaneous) is strongly linked to four fields of Psychology class and two fields of Social Sciences, but not to the other two interconnected fields of Arts and Humanities (dark red labels on the left). Four out of nine largest experience research fields under Social Sciences have no strong links to other experience research fields. The largest experience research field, Education, connects to almost all subject area classes weakly, but it does not have strong links to any other experience research field. Figure 8 gives some evidence of the weak links from Education to various research fields.

At the bottom of Fig. 7, one can see Health Sciences (brown labels). There are few strong links between the research fields in this area. Two of the three strong links connect different ASJC classes: Clinical Psychology and Health (Social Science), linked to Psychiatry and Mental Health and Health Policy, respectively. The only Life Sciences field included in the top 50 experience research fields, Behavioral Neuroscience, has no strong links to the other fields.

Figure 8 provides another view to the research profile by visualizing the 212 largest experience research fields by the average publication year of the experience publications classified under each of them. The average years are 2008 or later for all research fields in Fig. 8, reflecting the recent strong growth of the publication volumes. The colors show that the oldest publication sets are in Social Psychology, Clinical Psychology, and many physiology-related fields such as Behavioral Neuroscience. The newest health-related fields in experience research include Health Policy, Health Informatics, and Maternity and Midwifery. HCI is a fresh experience research field, but there are both older and newer 
Table 6 The most productive institutions publishing experience research across disciplines, and their share of all experience publications in the country (note: the data is based on Scopus API data, and the information is missing from $2152,4.1 \%$ of the records)

\begin{tabular}{|c|c|c|c|c|}
\hline Rank & Affiliation Name & Country & Records & $\%$ of Country \\
\hline 1 & University of Toronto & Canada & 355 & $12.6 \%$ \\
\hline 2 & King's College London & UK & 323 & $4.4 \%$ \\
\hline 3 & University of Gothenburg & Sweden & 318 & $16.1 \%$ \\
\hline 4 & University of Queensland & Australia & 282 & $8.0 \%$ \\
\hline 5 & The University of Sydney & Australia & 278 & $7.9 \%$ \\
\hline 6 & University College London UCL & UK & 268 & $3.6 \%$ \\
\hline 7 & Monash University & Australia & 257 & $7.3 \%$ \\
\hline 8 & The University of British Columbia & Canada & 257 & $9.1 \%$ \\
\hline 9 & KU Leuven & Belgium & 254 & $36.5 \%$ \\
\hline 10 & Delft University of Technology & Netherlands & 248 & $13.2 \%$ \\
\hline 11 & Maastricht University & Netherlands & 240 & $12.8 \%$ \\
\hline 12 & Karolinska Institutet & Sweden & 239 & $12.1 \%$ \\
\hline 13 & University of Manchester & UK & 234 & $3.2 \%$ \\
\hline 14 & University of Melbourne & Australia & 234 & $6.6 \%$ \\
\hline 15 & University of Oxford & UK & 231 & $3.1 \%$ \\
\hline 16 & Purdue University & USA & 225 & $1.5 \%$ \\
\hline 17 & Queensland University of Technology QUT & Australia & 217 & $6.1 \%$ \\
\hline 18 & Technische Universiteit Eindhoven & Netherlands & 215 & $11.4 \%$ \\
\hline 19 & Lunds Universitet & Sweden & 214 & $10.8 \%$ \\
\hline 20 & Tampere University of Technology & Finland & 208 & $16.2 \%$ \\
\hline 21 & Griffith University & Australia & 201 & $5.7 \%$ \\
\hline 22 & University of Nottingham & UK & 198 & $2.7 \%$ \\
\hline 23 & Aarhus Universitet & Denmark & 196 & $21.5 \%$ \\
\hline 24 & Pennsylvania State University & USA & 192 & $1.3 \%$ \\
\hline 25 & University of Washington, Seattle & USA & 192 & $1.3 \%$ \\
\hline 26 & Uppsala Universitet & Sweden & 190 & $9.6 \%$ \\
\hline 27 & University of Helsinki & Finland & 187 & $14.5 \%$ \\
\hline 28 & University of New South Wales, Australia & Australia & 187 & $5.3 \%$ \\
\hline 29 & Københavns Universitet & Denmark & 184 & $20.2 \%$ \\
\hline 30 & Umeå Universitet & Sweden & 181 & $9.2 \%$ \\
\hline 31 & Norges Teknisk-Naturvitenskapelige Universitet & Norway & 180 & $18.1 \%$ \\
\hline 32 & Universitetet i Oslo & Norway & 180 & $18.1 \%$ \\
\hline 33 & Aalto University & Finland & 179 & $13.9 \%$ \\
\hline 34 & University of Technology Sydney & Australia & 177 & $5.0 \%$ \\
\hline 35 & University of Alberta & Canada & 176 & $6.3 \%$ \\
\hline 36 & The University of North Carolina at Chapel Hill & USA & 166 & $1.1 \%$ \\
\hline 37 & University of Calgary & Canada & 165 & $5.9 \%$ \\
\hline 38 & Universiteit Gent & Belgium & 163 & $23.4 \%$ \\
\hline 39 & University of Texas at Austin & USA & 162 & $1.1 \%$ \\
\hline 40 & University of Cambridge & UK & 161 & $2.2 \%$ \\
\hline 41 & University of Michigan, Ann Arbor & USA & 161 & $1.1 \%$ \\
\hline 42 & University of Newcastle, Australia & Australia & 160 & $4.5 \%$ \\
\hline 43 & Aalborg Universitet & Denmark & 154 & $16.9 \%$ \\
\hline 44 & Linköpings universitet & Sweden & 154 & $7.8 \%$ \\
\hline 45 & University of Sheffield & UK & 153 & $2.1 \%$ \\
\hline 46 & Michigan State University & USA & 151 & $1.0 \%$ \\
\hline 47 & Hong Kong Polytechnic University & Hongkong & 150 & $28.7 \%$ \\
\hline 48 & Indiana University & USA & 150 & $1.0 \%$ \\
\hline 49 & University of Southampton & UK & 150 & $2.0 \%$ \\
\hline
\end{tabular}


Table 7 Top affiliations of 3443 publications categorized under Human-Computer Interaction

\begin{tabular}{|c|c|c|c|}
\hline Rank & Affiliation name & Country & Records \\
\hline 1 & Tampere University of Technology & Finland & 101 \\
\hline 2 & Technische Universiteit Eindhoven & Netherlands & 83 \\
\hline 3 & Nokia Corporation & (Multinational) & 73 \\
\hline 4 & Aalto University & Finland & 68 \\
\hline 5 & Universitat Salzburg & Austria & 60 \\
\hline 6 & Queensland University of Technology QUT & Australia & 55 \\
\hline 7 & Newcastle University, United Kingdom & UK & 50 \\
\hline 8 & University of York & UK & 44 \\
\hline 9 & University of Oulu & Finland & 41 \\
\hline 10 & University of Tampere & Finland & 40 \\
\hline 11 & Delft University of Technology & Netherlands & 39 \\
\hline 12 & Google LLC & (Multinational) & 37 \\
\hline 13 & University of Sussex & UK & 36 \\
\hline 14 & University of Technology Sydney & Australia & 34 \\
\hline 15 & Carnegie Mellon University & USA & 33 \\
\hline 15 & University College London UCL & UK & 33 \\
\hline 17 & Lancaster University & UK & 32 \\
\hline 18 & Korea Advanced Institute of Science and Technology & South Korea & 31 \\
\hline 19 & Aalborg Universitet & Denmark & 30 \\
\hline 19 & Aarhus Universitet & Denmark & 30 \\
\hline 19 & Ontario Tech University & Canada & 30 \\
\hline 19 & University of Nottingham & UK & 30 \\
\hline 23 & Indiana University & USA & 29 \\
\hline 23 & Technical University of Berlin & Germany & 29 \\
\hline 25 & University of Saskatchewan & Canada & 28 \\
\hline 25 & VTT Technical Research Centre of Finland & Finland & 28 \\
\hline 27 & Folkwang-Hochschule Essen & Germany & 26 \\
\hline 27 & University of Helsinki & Finland & 26 \\
\hline 29 & Georgia Institute of Technology & USA & 25 \\
\hline 29 & Ludwig-Maximilians-Universität München & Germany & 25 \\
\hline 29 & University of Northumbria & UK & 25 \\
\hline 32 & IT-Universitetet i København & Denmark & 24 \\
\hline 32 & Københavns Universitet & Denmark & 24 \\
\hline 32 & National University of Singapore & Singapore & 24 \\
\hline 32 & Universitat Basel & Switzerland & 24 \\
\hline 32 & Universität Duisburg-Essen & Germany & 24 \\
\hline 37 & Microsoft Corporation & (Multinational) & 23 \\
\hline 37 & University of Jyvaskyla & Finland & 23 \\
\hline 37 & University of Leicester & UK & 23 \\
\hline 40 & Madeira Interactive Technologies Institute & Portugal & 22 \\
\hline 40 & Norges Teknisk-Naturvitenskapelige Universitet & Norway & 22 \\
\hline 40 & Simon Fraser University & Canada & 22 \\
\hline 40 & University of Melbourne & Australia & 22 \\
\hline 44 & KU Leuven & Belgium & 21 \\
\hline 44 & University College Cork & Ireland & 21 \\
\hline 46 & University of Waterloo & Canada & 20 \\
\hline
\end{tabular}

fields under the Computer Science class. Marketing stands out as a recently active field publishing experience research among the business-related experience research fields.
Finally, Fig. 9 shows the strongest connections from $\mathrm{HCI}$ to the other experience research fields. The strength of a link indicates the volume of experience publications in venues that are classified to both of the linked research fields, and 
Table 8 Experience authors with 20 or more publications in the sample

\begin{tabular}{|c|c|c|c|c|c|c|c|c|}
\hline & Name & $\#$ & CExp & $\mathrm{HiC}$ & h-ix & Avg & Subject area (most common) & $\mathrm{X}$-Disc \\
\hline 1 & Tscheligi M & 74 & 541 & 63 & 12 & 7.3 & Human-Computer Interaction & 6 \\
\hline 2 & Van Os J & 66 & 2639 & 346 & 26 & 40.0 & Psychiatry and Mental health & 8 \\
\hline 3 & Väänänen-Vainio-Mattila K & 62 & 937 & 222 & 16 & 15.1 & Human-Computer Interaction & 8 \\
\hline 4 & Szczerbicki E & 61 & 363 & 39 & 11 & 6.0 & Artificial Intelligence & 7 \\
\hline 5 & Myin-Germeys I & 60 & 2064 & 174 & 18 & 34.4 & Psychiatry and Mental health & 7 \\
\hline 6 & Sanín C & 59 & 362 & 39 & 11 & 6.1 & Artificial Intelligence & 7 \\
\hline 7 & Hassenzahl M & 49 & 1654 & 408 & 18 & 33.8 & Human-Computer Interaction & 7 \\
\hline 8 & Nacke L & 44 & 743 & 150 & 13 & 16.9 & Human-Computer Interaction & 3 \\
\hline 8 & Obrist M & 44 & 603 & 222 & 12 & 13.7 & Human-Computer Interaction & 6 \\
\hline 10 & Elliott M & 38 & 1043 & 248 & 14 & 27.4 & Health Policy & 6 \\
\hline 11 & Law E & 36 & 969 & 408 & 9 & 26.9 & Human-Computer Interaction & 7 \\
\hline 12 & Kwapil T.R & 34 & 681 & 90 & 17 & 20.0 & Psychiatry and Mental health & 7 \\
\hline 12 & Roto V & 34 & 1151 & 408 & 13 & 33.9 & Human-Computer Interaction & 10 \\
\hline 12 & Wright P & 34 & 723 & 148 & 11 & 21.3 & Human-Computer Interaction & 7 \\
\hline 15 & Delespaul P.A.E.G & 32 & 1394 & 174 & 18 & 43.6 & Psychiatry and Mental health & 7 \\
\hline 16 & Schifferstein H.N.J & 31 & 897 & 239 & 16 & 28.9 & Computer Graphics and Computer-Aided Design & 13 \\
\hline 17 & Denenberg V.H & 30 & 1482 & 373 & 17 & 49.4 & Behavioral Neuroscience, Developmental Biology, Medicine (all) & 5 \\
\hline 17 & Riva G & 30 & 270 & 64 & 8 & 9.0 & Rehabilitation, Neuroscience, Psychology, CS (miscellaneous) & 9 \\
\hline 17 & Schatz R & 30 & 680 & 157 & 14 & 22.7 & Computer Networks and Communications & 4 \\
\hline 17 & Timmerer $\mathrm{C}$ & 30 & 371 & 39 & 11 & 12.4 & Computer Graphics and Computer-Aided Design & 4 \\
\hline 21 & Ebrahimi T & 29 & 405 & 69 & 10 & 14.0 & Software & 6 \\
\hline 21 & Mellouk A & 29 & 164 & 28 & 7 & 5.7 & Computer Networks and Communications & 3 \\
\hline 21 & Silvia P.J & 29 & 986 & 121 & 19 & 34.0 & Developmental and Educational Psychology & 6 \\
\hline 24 & Fiedler M & 28 & 202 & 85 & 6 & 7.2 & Computer Networks and Communications & 6 \\
\hline 25 & Gandour J & 27 & 1215 & 255 & 18 & 45.0 & Cognitive Neuroscience, Experimental and Cognitive Psychology & 9 \\
\hline 25 & Johnson D & 27 & 184 & 30 & 9 & 6.8 & Human-Computer Interaction & 6 \\
\hline 25 & Liotta A & 27 & 289 & 44 & 10 & 10.7 & Computer Networks and Communications & 6 \\
\hline 25 & Muntean G.M & 27 & 433 & 114 & 10 & 16.0 & Electrical and Electronic Engineering & 4 \\
\hline 25 & Swendsen J.D & 27 & 687 & 87 & 17 & 25.4 & Psychiatry and Mental health & 6 \\
\hline 25 & Wichers M & 27 & 648 & 162 & 11 & 24.0 & Psychiatry and Mental health & 9 \\
\hline 31 & Häkkilä J & 26 & 194 & 35 & 8 & 7.5 & Human-Computer Interaction & 3 \\
\hline 32 & De Turck F & 25 & 253 & 52 & 8 & 10.1 & Computer Networks and Communications & 6 \\
\hline 32 & Krishnan A & 25 & 1163 & 255 & 16 & 46.5 & Cognitive Neuroscience, Experimental and Cognitive Pscyhology & 9 \\
\hline 32 & Mirza-Babaei P & 25 & 129 & 39 & 6 & 5.2 & Human-Computer Interaction & 2 \\
\hline 32 & Wyeth P & 25 & 253 & 77 & 9 & 10.1 & Human-Computer Interaction & 4 \\
\hline 36 & Lee J.S & 24 & 274 & 69 & 8 & 11.4 & Computer Vision and Pattern Recognition, Media Technology & 2 \\
\hline 36 & Meschtscherjakov A & 24 & 170 & 63 & 7 & 7.1 & Human-Computer Interaction & 4 \\
\hline 38 & Benford S & 23 & 627 & 217 & 9 & 27.3 & Human-Computer Interaction & 4 \\
\hline 38 & Desmet P.M.A & 23 & 988 & 506 & 8 & 43.0 & Computer Graphics and Computer-Aided Design & 13 \\
\hline 38 & Gonzalez C & 23 & 391 & 100 & 10 & 17.0 & Applied Psychology & 9 \\
\hline 38 & Kara P.A & 23 & 105 & 12 & 6 & 4.6 & Media Technology & 4 \\
\hline 38 & Lundgren I & 23 & 536 & 68 & 12 & 23.3 & Obstetrics and Gynaecology & 4 \\
\hline 38 & Turunen M & 23 & 145 & 40 & 6 & 6.3 & Human-Computer Interaction & 6 \\
\hline 44 & Hildingsson I & 22 & 423 & 68 & 12 & 19.2 & Obstetrics and Gynaecology & 2 \\
\hline 44 & Jacobs N & 22 & 877 & 162 & 13 & 39.9 & Psychiatry and Mental health & 9 \\
\hline 44 & Lehto X.Y & 22 & 382 & 69 & 11 & 17.4 & Tourism, Leisure and Hospitality Management & 4 \\
\hline 44 & Marcus A & 22 & 68 & 17 & 5 & 3.1 & Computer Science (all), Theoretical CS & 3 \\
\hline 44 & Martini M.G & 22 & 107 & 24 & 6 & 4.9 & Media Technology & 3 \\
\hline 44 & McCarthy J & 22 & 592 & 148 & 11 & 26.9 & Human-Computer Interaction & 6 \\
\hline 44 & Pakanen M & 22 & 77 & 17 & 5 & 3.5 & Human-Computer Interaction & 4 \\
\hline
\end{tabular}


Table 8 (continued)

\begin{tabular}{|c|c|c|c|c|c|c|c|c|}
\hline & Name & \# & CExp & $\mathrm{HiC}$ & h-ix & Avg & Subject area (most common) & $\mathrm{X}$-Disc \\
\hline 44 & Väätäjä H & 22 & 86 & 20 & 6 & 3.9 & Human-Computer Interaction & 4 \\
\hline 44 & Wu C.-H & 22 & 404 & 86 & 12 & 18.4 & Tourism, Leisure and Hospitality Management & 7 \\
\hline 53 & Bernhaupt R & 21 & 166 & 30 & 7 & 7.9 & Human-Computer Interaction & 5 \\
\hline 53 & Bidelman G.M & 21 & 563 & 78 & 13 & 26.8 & Neuroscience (all) & 8 \\
\hline 53 & Diefenbach S & 21 & 579 & 247 & 9 & 27.6 & Human-Computer Interaction & 4 \\
\hline 53 & Happell B & 21 & 480 & 87 & 13 & 22.9 & Phychiatric Mental Health & 3 \\
\hline 53 & Hertwig R & 21 & 695 & 157 & 11 & 33.1 & Developmental and Educational Psychology & 9 \\
\hline 53 & Häkkinen J & 21 & 208 & 47 & 8 & 9.9 & Electrical and Electronic Engineering, $\mathrm{HCI}$ & 7 \\
\hline 53 & Le Callet P & 21 & 258 & 58 & 9 & 12.3 & Electrical and Electronic Engineering & 5 \\
\hline 53 & Möller S & 21 & 51 & 14 & 4 & 2.4 & Safety, Risk, Reliability and Quality & 7 \\
\hline 53 & Ziebland S & 21 & 664 & 182 & 14 & 31.6 & Medicine (all), Public Health, Environmental and Occup. Health & 5 \\
\hline 62 & Arhippainen L & 20 & 80 & 17 & 6 & 4.0 & Computer Networks and Communications & 4 \\
\hline 62 & Bordegoni M & 20 & 62 & 12 & 5 & 3.1 & Computer Graphics and Computer-Aided Design & 7 \\
\hline 62 & Cerqueira $\mathrm{E}$ & 20 & 107 & 19 & 5 & 5.4 & Computer Networks and Communications & 3 \\
\hline 62 & Hakulinen J & 20 & 144 & 40 & 6 & 7.2 & Human-Computer Interaction & 7 \\
\hline 62 & Hays R.D & 20 & 647 & 248 & 10 & 32.4 & Health Policy & 5 \\
\hline 62 & McGrath J & 20 & 496 & 129 & 11 & 24.8 & Psychiatry and Mental health & 3 \\
\hline 62 & Pearce P.L & 20 & 293 & 58 & 10 & 14.7 & Tourism, Leisure and Hospitality Management & 3 \\
\hline 62 & Raake A & 20 & 213 & 53 & 8 & 10.7 & Human-Computer Interaction & 5 \\
\hline 62 & Raballo A & 20 & 479 & 104 & 11 & 24.0 & Psychiatry and Mental health & 7 \\
\hline 62 & Sackl A & 20 & 161 & 27 & 8 & 8.1 & Human-Computer Interaction & 4 \\
\hline 62 & Wurhofer D & 20 & 109 & 19 & 6 & 5.5 & Human-Computer Interaction & 6 \\
\hline
\end{tabular}

$\mathrm{CExp}=$ citations (to articles in the sample), $\mathrm{HiC}=$ highest citations to one publication, $\mathrm{h}-\mathrm{ix}=\mathrm{H}$-index within the sample, Avg $=\mathrm{Average}$ of citations within the sample, $\mathrm{X}$-Disc $=$ Cross-disciplinarity (nr. of ASJC Mid subject areas for author's publications)

only the links with at least 50 publications are visible. For example, the link between $H C I$ and Psychology (all) exists, because Computers in Human Behavior journal is classified under $\mathrm{HCI}$ and Psychology (all), and there are 149 articles from this journal in our data set. By this measure, $\mathrm{HCI}$ is a relatively multidisciplinary experience research field.

\section{Discussion}

This broad research profiling analysis of experience research provides visibility to experience research across all disciplines. Besides the author performance analyses, we applied various science mapping techniques to the bibliographic data of 51,901 publications. For the first time, we can see an overview of experience research across disciplines, the prominent experience research fields, locations, and authors studying human experiences, as well as the most cited publications in this area and cross-citations between research fields. Based on the research profiling results reported in the previous chapter, we now answer our original questions and discuss the limitations of our study before the final conclusions.

\section{How the volumes of experience research have developed?}

The experience publication volumes over 125 years evidence the rapidly growing interest in experience research (Figs. 1, $2,3)$. Almost a quarter $(23.5 \%)$ of the publications in our data set were published during the last two years alone. Especially publications in Education and Psychiatry and Mental Health have been growing, while the growth in the HCI field has remained modest during years 2016-2018. This may imply a possible stagnation of experience research in $\mathrm{HCI}$, or maturation of it towards more specific aspects of user experience, such as non-instrumental or emotional value, interaction aesthetics, or eudaimonia for the hedonic side of user experience. Investigating the terms used for experience research in $\mathrm{HCI}$ would be a highly interesting, but a challenging endeavor and would require a separate study. The experience research volumes in the other fields of Computer Science have grown more during this period than in $H C I$ (a subfield of Computer Science), which shows that experience research has obtained a footing in Computer Science research also outside the $H C I$ field. Still, with about 400 annual experience publications, $\mathrm{HCI}$ is the $3 \mathrm{rd}$ largest 
Table 9 The most cited authors by experience researchers

\begin{tabular}{|c|c|c|c|c|}
\hline & Cited author & Records & Instances & Topics with $100+$ citations in our data set \\
\hline 1 & Csikszentmihalyi, $\mathrm{M}$ & 2050 & 4087 & Flow experience, Experience sampling \\
\hline 2 & Kolb, D. A & 1869 & 2782 & Experiential learning, Learning styles \\
\hline 3 & Strauss, A. L & 1750 & 2221 & Grounded theory, Qualitative research \\
\hline 4 & Gilmore, J. H & 1379 & 1833 & Experience economy \\
\hline 5 & Lincoln, Y.S & 1363 & 1520 & Naturalistic inquiry \\
\hline 6 & Hassenzahl, M & 1346 & 2952 & User experience, Experience design \\
\hline 7 & Dewey, J & 1327 & 2091 & Experience and education, Experience and nature, How we think \\
\hline 8 & Pine, B. J & 1287 & 1626 & Experience economy \\
\hline 9 & Cohen, $\mathrm{J}$ & 1250 & 1339 & $\begin{array}{l}\text { Power analysis, Multiple regression / correlation analysis, A power } \\
\text { primer }\end{array}$ \\
\hline 10 & Holbrook, M. B & 1123 & 2025 & Experiential / Hedonic consumption \\
\hline 11 & Norman, D. A & 1101 & 1370 & Emotional design, Psychology of things \\
\hline 12 & Parasuraman, A & 1085 & 1796 & Customer experience, ServQual scale, Service quality \\
\hline 13 & Corbin, J & 1076 & 1168 & Grounded theory \\
\hline 14 & Kahneman, D & 1051 & 1787 & Prospect theory, Day Reconstruction Method, Thinking fast and slow \\
\hline 15 & Zeithaml, V. A & 997 & 1704 & ServQual scale, Consumer perceptions \\
\hline 16 & Guba, E. G & 985 & 1036 & Naturalistic inquiry \\
\hline 17 & Fornell, C & 970 & 1187 & Structural equation models \\
\hline 18 & Bandura, A & 952 & 1452 & Self-efficacy, Social cognitive theory \\
\hline 19 & Schmitt, B. H & 943 & 1612 & Brand experience, Experiential marketing \\
\hline 20 & Patton, M. Q & 913 & 927 & Qualitative research and evaluation \\
\hline 21 & Clarke, V & 895 & 942 & Thematic analysis in psychology \\
\hline 22 & Braun, V & 887 & 931 & Thematic analysis in psychology \\
\hline 23 & Ryan, R. M & 885 & 1677 & Self-Determination Theory \\
\hline 24 & Glaser, B. G & 875 & 1070 & Grounded theory \\
\hline 25 & Watson, D & 856 & 1207 & PANAS scale \\
\hline 26 & Larcker, D. F & 818 & 831 & Structural equation models \\
\hline 27 & Hirschman, E. C & 803 & 1020 & Hedonic / Experiential consumption \\
\hline 28 & Oliver, R. L & 800 & 1381 & Consumer satisfaction and loyalty \\
\hline 29 & Nielsen, J & 798 & 1114 & Usability engineering \\
\hline 30 & Mearleau-Ponty, M & 760 & 946 & Phenomenology of perception \\
\hline
\end{tabular}

Records $=\mathrm{Nr}$. of experience publications citing the author Instances $=$ Total number of citations found in experience publications for the author Topic $=$ the highest cited work(s) of the author

Fig. 6 Number of experience publications ( $\mathrm{x}$ axis) receiving $\mathrm{y}$ citations (y axis)
Citations to publications

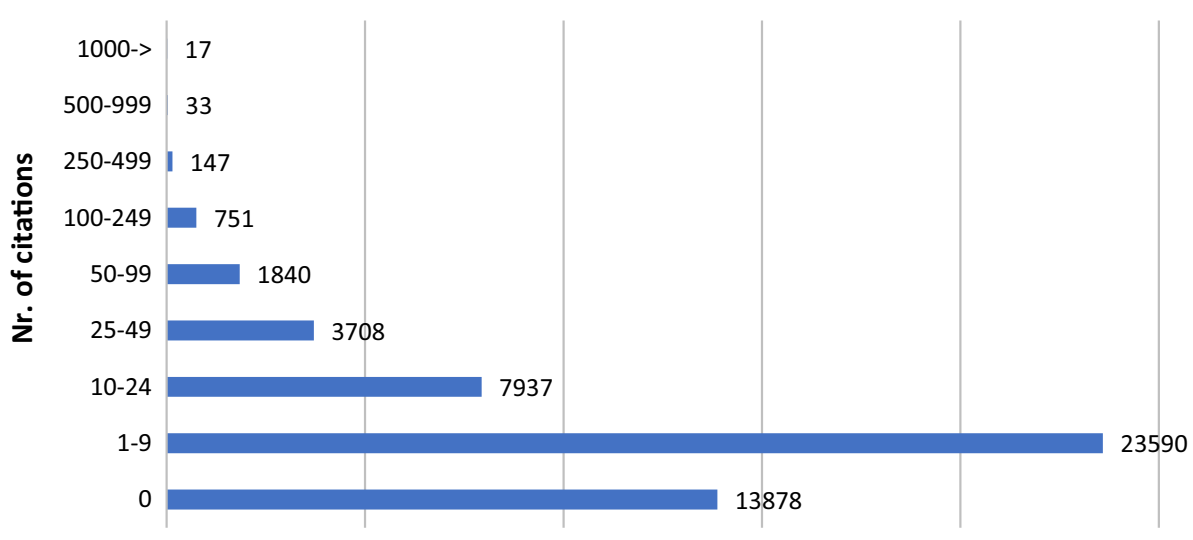

Nr. of publications having y amount of citations 
Table 10 Experience publications with 1000 + citations in Scopus by March 2019

Publication
Gratz, K.L. \& Roemer, L. (2004). Multidimensional Assessment
of Emotion Regulation and Dysregulation: Development, Factor
Structure, and Initial Validation of the Difficulties in Emotion
Regulation Scale. Journal of Psychopathology and Behavioral
Assessment, 26, 41-54
Nunez, P. L. \& Srinivasan, R. (2009). Electric fields of the Brain:
The neurophysics of EEG. Oxford Scholarship Online
Mandler, G. (1980). Recognizing: The judgment of previous occur-
rence. Psychological Review, 87(3), 252-271
Nicholls, J.G. (1984). Achievement motivation: Conceptions of
ability, subjective experience, task choice, and performance.
Psychological review, 91(3), 328-346
Sarason, I. G., Johnson, J. H., \& Siegel, J. M. (1978). Assessing
the impact of life changes: Development of the life experiences
survey. Journal of Consulting and Clinical Psychology, 46(5),
932-946

Bolger, N., Davis, A., \& Rafaeli, E. (2003). Diary methods: Capturing life as it is lived. Annual Review of Psychology, 54, 579-616

O'Regan, J. K., \& Noë, A. (2001). A sensorimotor account of vision and visual consciousness. Behavioral and Brain Sciences, 24(5), 939-973

Johanson, J., \& Vahlne, J.-E. (2009). The uppsala internationalization process model revisited: From liability of foreignness to liability of outsidership. Journal of International Business Studies, 40(9), 1411-1431

Shiffman, S., Stone, A. A., \& Hufford, M. R. (2008). Ecological momentary assessment, Annual Review of Clinical Psychology, 4, 1-32

Rivkin, S. G., Hanushek, E. A., \& Kain, J. F. (2005). Teachers, schools, and academic achievement. Econometrica, 73(2), 417-458

Wetzels, M., Odekerken-Schröder, G., \& Van Oppen, C. (2009). Using PLS path modeling for assessing hierarchical construct models: Guidelines and empirical illustration. MIS Quarterly, 33(1), 177-196

Taylor, S., \& Todd, P. (1995). Assessing IT usage: The role of prior experience. MIS Quarterly, 19(4), 561-568

Tellegen, A., \& Atkinson, G. (1974). Openness to absorbing and self-altering experiences ("absorption"), a trait related to hypnotic susceptibility. Journal of Abnormal Psychology, 83(3), 268-277

Wang, N. (1999). Rethinking authenticity in tourism experience. Annals of Tourism Research, 26(2), 349-370

Cohen, E. (1988). Authenticity and commoditization in tourism. Annals of Tourism Research, 15(3), 371-386

Diener, E., \& Emmons, R. A. (1984). The independence of positive and negative affect. Journal of Personality and Social Psychology, 47(5), 1105-1117

Bontis, N. (1998). Intellectual capital: An exploratory study that develops measures and models. Management Decision, 36(2), $63-76$

\section{ASJC Mid Subject Areas}

Psychology

Cit

Neuroscience

1959

Psychology; Arts and Humanities

Psychology; Arts and Humanities

Psychology; Medicine

Psychology

Psychology; Biochemistry, Genetics and Molecular Biology; Neuroscience

Economics, Econometrics and Finance; Business, Management and Accounting

Psychology; Medicine

Economics, Econometrics and Finance

Business, Management and Accounting; Computer Science; Decision Sciences

Same as above

Psychology

Social Sciences; Business, Management and Accounting

Same as above

Social Sciences; Psychology

Business, Management and Accounting; Decision Sciences

1048 experience research field of all times, despite its short life compared to that of Psychology or Education.

Which disciplines study experiences? Experience research has its origins in Psychology, but it has expanded to many disciplines since the 1970's. According to our research profiling study, Education is the largest field of experience research. Many disciplines publish educational research around learning through experience, such as experiential learning. Further research is required in this vast set of literature to find out evidence whether experience research in 
Table 11 Most cited publications under Computer Science category in our data set

Computer Science (ASJC MID subject area class) Cit

1 Wetzels, M., Odekerken-Schröder, G., \& Van Oppen, C. (2009). Using PLS path modeling for assessing hierarchical construct 1296 models: Guidelines and empirical illustration. MIS Quarterly: Management Information Systems, 33(1), 177-196

2 Taylor, S., \& Todd, P. (1995). Assessing IT usage: The role of prior experience. MIS Quarterly: Management Information Systems, 19(4), 561-568

3 Hsu, C. -., \& Lu, H. -. (2004). Why do people play on-line games? an extended TAM with social influences and flow experience. Information and Management, 41(7), 853-868

4 Conway, M. A. (2005). Memory and the self. Journal of Memory and Language, 53(4), 594-628

Mudambi, S. M., \& Schuff, D. (2010). What makes a helpful online review? A study of customer reviews on amazon.com. MIS Quarterly: Management Information Systems, 34(1), 185-200

6 Basili, V. R., \& Dieter Rombach, H. (1988). The TAME project: Towards improvement-oriented software environments. IEEE Transactions on Software Engineering, 14(6), 758-773

7 Brodie, R. J., Hollebeek, L. D., Jurić, B., \& Ilić, A. (2011). Customer engagement: Conceptual domain, fundamental propositions, and implications for research. Journal of Service Research, 14(3), 252-271

8 Kiili, K. (2005). Digital game-based learning: Towards an experiential gaming model. Internet and Higher Education, 8(1), 13-24

9 Bhatt, G. D., \& Grover, V. (2005). Types of information technology capabilities and their role in competitive advantage: An empirical study. Journal of Management Information Systems, 22(2), 253-277

10 Desmet, P., \& Hekkert, P. (2007). Framework of product experience. International Journal of Design, 1(1), 57-66

11 Corbitt, B. J., Thanasankit, T., \& Yi, H. (2003). Trust and e-commerce: A study of consumer perceptions. Electronic Commerce Research and Applications, 2(3), 203-215

12 Awad, N. F., \& Krishnan, M. S. (2006). The personalization privacy paradox: An empirical evaluation of information transparency and the willingness to be profiled online for personalization. MIS Quarterly: Management Information Systems, 30(1), 13-28

13 Law, E. L. C., Roto, V., Hassenzahl, M., Vermeeren, A. P. O. S., \& Kort, J. (2009). Understanding, scoping and defining user experience: A survey approach. Paper presented at the Conference on Human Factors in Computing Systems-Proceedings, 719-728

14 Kolodner, J. L. (1992). An introduction to case-based reasoning. Artificial Intelligence Review, 6(1), 3-34

15 Seaborn, K., \& Fels, D. I. (2015). Gamification in theory and action: A survey. International Journal of Human Computer Studies, 74, 14-31

16 Durndell, A., \& Haag, Z. (2002). Computer self efficacy, computer anxiety, attitudes towards the internet and reported experience with the internet, by gender, in an east european sample. Computers in Human Behavior, 18(5), 521-535

17 Yoo, Y. (2010). Computing in everyday life: A call for research on experiential computing. MIS Quarterly: Management Information Systems, 34(SPEC. ISSUE 2), 213-231

18 Ha, I., Yoon, Y., \& Choi, M. (2007). Determinants of adoption of mobile games under mobile broadband wireless access environment. Information and Management, 44(3), 276-286

19 Zomerdijk, L. G., \& Voss, C. A. (2010). Service design for experience-centric services. Journal of Service Research, 13(1), 67-82

20 Lee, C. S., \& Ma, L. (2012). News sharing in social media: The effect of gratifications and prior experience. Computers in Human Behavior, 28(2), 331-339

the Education area focuses on cognitive development, or whether emotional experiences are becoming prominent along with increased online education and gamification. Other prominent experience research fields include several fields under Computer science (Software and $\mathrm{HCI}$ as the largest ones) Psychology, Psychiatry and mental health, Public, environmental and occupational health, and Tourism, leisure and hospitality management (Table 1).

One of the clear findings of our high-level profiling analysis is that experience is a truly multi-disciplinary research topic, since the publications in our data set cover 326 out of 334 ASJC research fields. Now that we have a birds-eye view to experience research across disciplines, scholars can better navigate between the fields and learn from the knowledge gained in the different fields. It will be intriguing to see which theories, methods and measures are used across research fields and which of them are still unique for a certain discipline.

Where are the experience research hubs? A majority (55\%) of experience publications come from the United States, United Kingdom, Australia, and Canada (Table 3). The list is dominated by countries from the Western and Asian cultures, which may communicate the importance of experiences in these contexts. While experience economy was born and studied first in the Western cultures, aesthetic experiences are deeply rooted in Asian cultures.

It is also interesting to see which countries are the most active compared to the population size. European countries form the top 6 countries of experience research, with more 


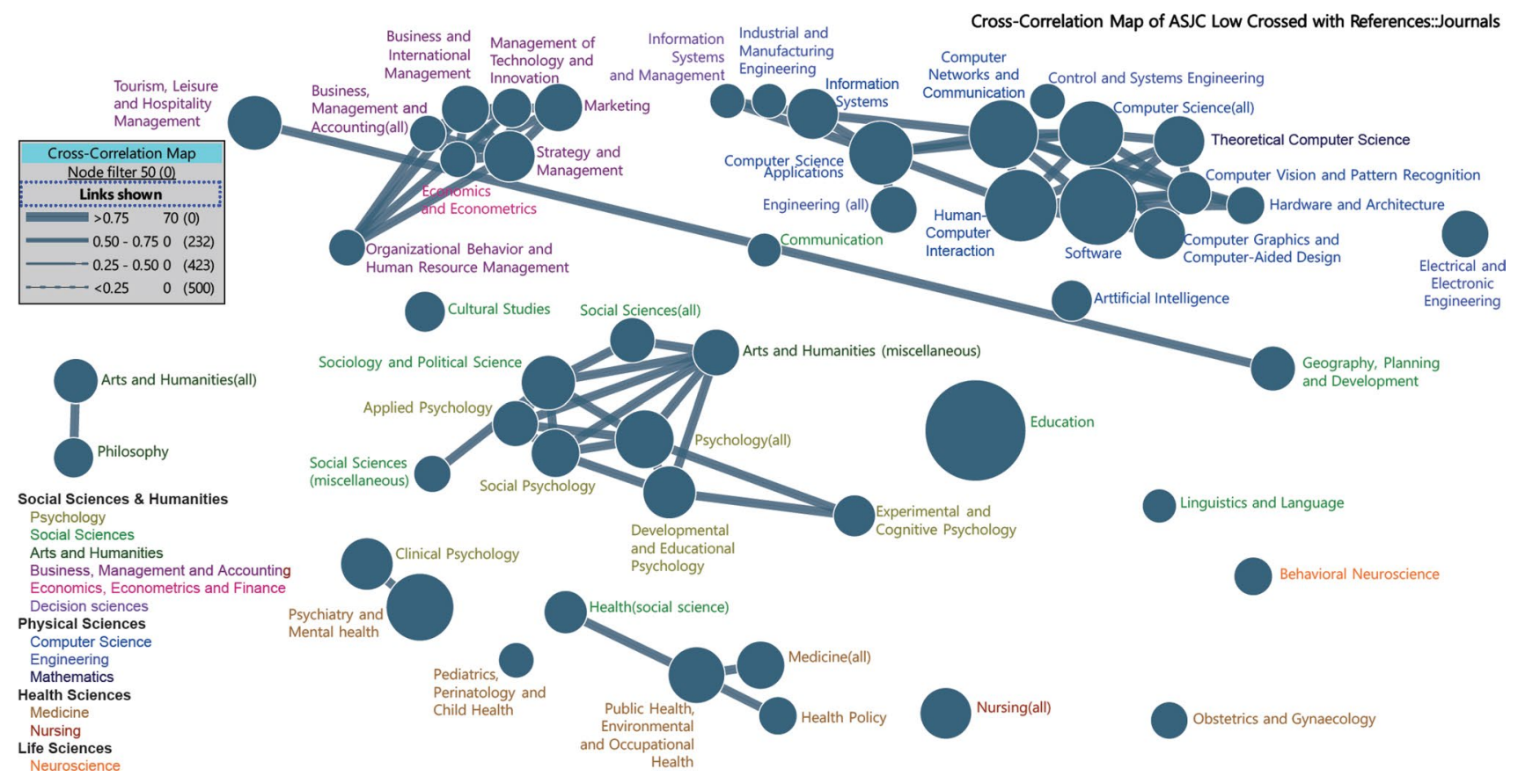

Fig. 7 The most frequent cross-citations between experience research fields

than 11 experience publications per million inhabitants. The leading countries Finland, Denmark, Ireland, Sweden and the Netherlands are currently among the 13 Tier 1 countries in Social Progress Index, ${ }^{2}$ and Austria coming close on the 15 th position. This may mean that understanding experiences becomes the more important the higher the quality of life is. The reason for the high interest in experience research in the Nordic countries may be the democratic culture with the Scandinavian movement in participatory design, leading the focus on employee, customer, patient, and user experiences.

There are interesting differences between countries regarding the research fields in which experiences are studied (Table 4). For example, if one wants to find experts of healthcare-related experiences, it seems that Sweden, Norway, and UK are the countries to look for. Especially Sweden excels in medicine and healthcare related experience research, as health is at the top of Swedish experience research, and 6 out of the top 10 experience research fields are in this area. In contrast, experience research of technology related experiences is strong in many Asian countries based on the popularity of several Computer science fields and Electrical and electronic engineering in the top ten fields of China, apan, and South Korea (Table 4). India seems to have active research around experience economy, as several business school topics are on its top ten list, such

\footnotetext{
$2 \mathrm{https}: / / \mathrm{www}$. socialprogress.org is known as a quality-of-life index.
}

as Marketing as the 2nd most popular experience research topic.

According to this study, the most prolific experience research units of all times are the University of Toronto in Canada, King's College London in United Kingdom, and University of Gothenburg in Sweden (Table 6). Despite the leading position of the United States in experience research, there is no single university as a global hub there, but experience research is distributed between hundreds of universities. Purdue University holds the highest position (16.) on the global list, with its $1.5 \%$ share of the national experience research.

In $H C I$, the most productive experience research hubs are Tampere University of Technology in Finland, Technische Universiteit Eindhoven in the Netherlands, and Nokia Corporation with headquarters in Finland (Table 7). It is notable that the position of Tampere as the global hub of experience research in $\mathrm{HCI}$ area has become even stronger with the recent merger of the two prominent universities in Tampere. Also Google and Microsoft are listed among the top 40 experience research hubs in the $H C I$ field, which shows the importance of UX research to the software industry. Perhaps because of Nokia, experience research in Finland has been very active, and Finnish research institutions hold half of the top ten positions on Table 7.

Who are the most active or influential experience researchers? About a third of the most prolific authors of all times in experience research publish in $\mathrm{HCI}$ venues. 
Manfred Tscheligi from the University of Salzburg, publishing primarily in the $\mathrm{HCI}$ field, holds the first position on the list of most productive experience researchers with his 74 publications in our data set (Table 8). Also the third position goes to a HCI researcher, Kaisa Väänänen-Vainio-Mattila, who has published 62 publications, more than half of the 101 HCI publications from the Tampere University of Technology. Jim van Os holds the second position by 66 experience publications in the field of Psychiatry and Mental Health. $\mathrm{He}$ is also the most influential experience researcher with an h-index of 26 within our set. The second position of impact among experience researchers goes to Paul Silvia (h-index 19, Developmental and Educational Psychology). The third position is shared by four scholars with an h-index of 18 : Inez Myin-Germeys and Philippe Delespaul, both publishing primarily in Psychiatry and Mental Health, Marc Hassenzahl (HCI), and Jack Gandour (Cognitive Neuroscience and Experimental and Cognitive Psychology).

Which works are the most cited by experience researchers? The most cited author in our data set is Mihali Csikszentmihalyi (Table 9), best known of the concept of Flow, an optimal experience where one is fully concentrated in an activity with a an appropriate combination of challenge and skill level and where the other concerns are ignored [11]. Csikszentmihalyi has also co-developed Experience Sampling method to study experiences in the daily lives of people [29]. The second most cited author by experience researchers is David A. Kolb. His most cited publication is a book on Experiential Learning, which states a model for learning through active experimentation, concrete experience, reflective observation, and abstract conceptualization [28]. The third most cited author in the experience publications is Anselm L. Strauss, who co-developed the Grounded Theory, a methodology for forming theory based on qualitative empirical data [18]. Three $\mathrm{HCI}$ researchers make it to the list of the top 30 cited authors: Marc Hassenzahl (user experience), Donald Norman (emotional design), and Jakob Nielsen (usability engineering). The appearance of usability engineering in this list hints about the mixture of terms user experience and usability.

The most cited works approach experience from several angles: the subjects or objects of experience, the phenomenon of the experience itself, the phenomena around experiences, or the methods for studying experiences. The research on the subjects of experience study the people experiencing, such as User experience [23] or Customer experience [50]. Studies focusing on the objects of experience investigate the artefacts that influence the experience, such as Brand experience [7] or Service quality [36]. Research on the experience itself can be exemplified by the highly cited works on Flow [11], Self-efficacy [1], and Experiential learning [28]. The phenomena around experience in Table 9 cover Experience economy Pine and Gilmore [38, 39] and Consumer loyalty
[7]. The most cited publications by experience researchers include many methodological works, such as Experience Sampling [29], Grounded Theory [18], or Naturalistic Inquiry [32], and the popular philosophies and theories that experience research leans on include Phenomenology [33] and Social Cognitive Theory [2].

Most of the topics in Table 9 have been addressed in $\mathrm{HCI}$ research. However, Naturalistic Inquiry seems to be a rare term in $\mathrm{HCI}$ publications, although $\mathrm{HCI}$ does utilize the methods encompassed by Naturalistic Inquiry: case studies with participant observations, interviews, and grounded theory. Similarly, few $\mathrm{HCI}$ scholars refer to Patton's qualitative research methods [37], while Patton is highly cited by other experience researchers.

How are different experience research disciplines linked? The cross-correlations in Fig. 7 depict a tight linkage between the experience research fields under Computer Science ASJC class, but the connections to other experience research fields are weak. Similarly, the tight internal but weak external bonding can be seen in the experience research fields under the Business, Management and Accounting class. Another extreme is Education, the largest field of experience research, which seems an isolated bubble in Fig. 7 More detailed investigation of Fig. 8 shows Education is highly connected to the other disciplines, but none of the links are strong enough to be visible in Fig. 7. All experience research fields under Psychology class are strongly connected to at least one other experience research field, also in other ASJC classes, which shows the importance of Psychology to experience research. In summary, while there are strong links between the experience research fields within a discipline, the different disciplines are rather isolated from each other.

How is $\mathrm{HCI}$ field situated on the map of experience research? $\mathrm{HCI}$ is the third largest area of experience research, and there are $8 \mathrm{HCI}$ researchers among the 15 most prolific authors of experience publications (Table 8). While $H C I$ actively publishes experience research, there are not many citations to $\mathrm{HCI}$ publications. Only $3 \mathrm{HCI}$ researchers are found from the top 30 cited authors list: Marc Hassenzahl, Donald Norman, and Jakob Nielsen (Table 9). The low number of citations may be due to the surprising use of the term 'user experience' in $\mathrm{HCI}$ field. The appearance of usability engineering researcher Jakob Nielsen in the top 30 'experience research superstars' without any publications in our data set supports the finding by Bargas-Avila and Hornbaek [4] that researchers tend to use the user experience term as a synonym for usability. Researchers working on memorable experiences for customers by staging meaningful, valuable and eudamonic experiences may find $\mathrm{HCl}$ 's focus on efficient, problem-free interactions lame. Some researchers use UX as a synonym for user interface, although experience is a 


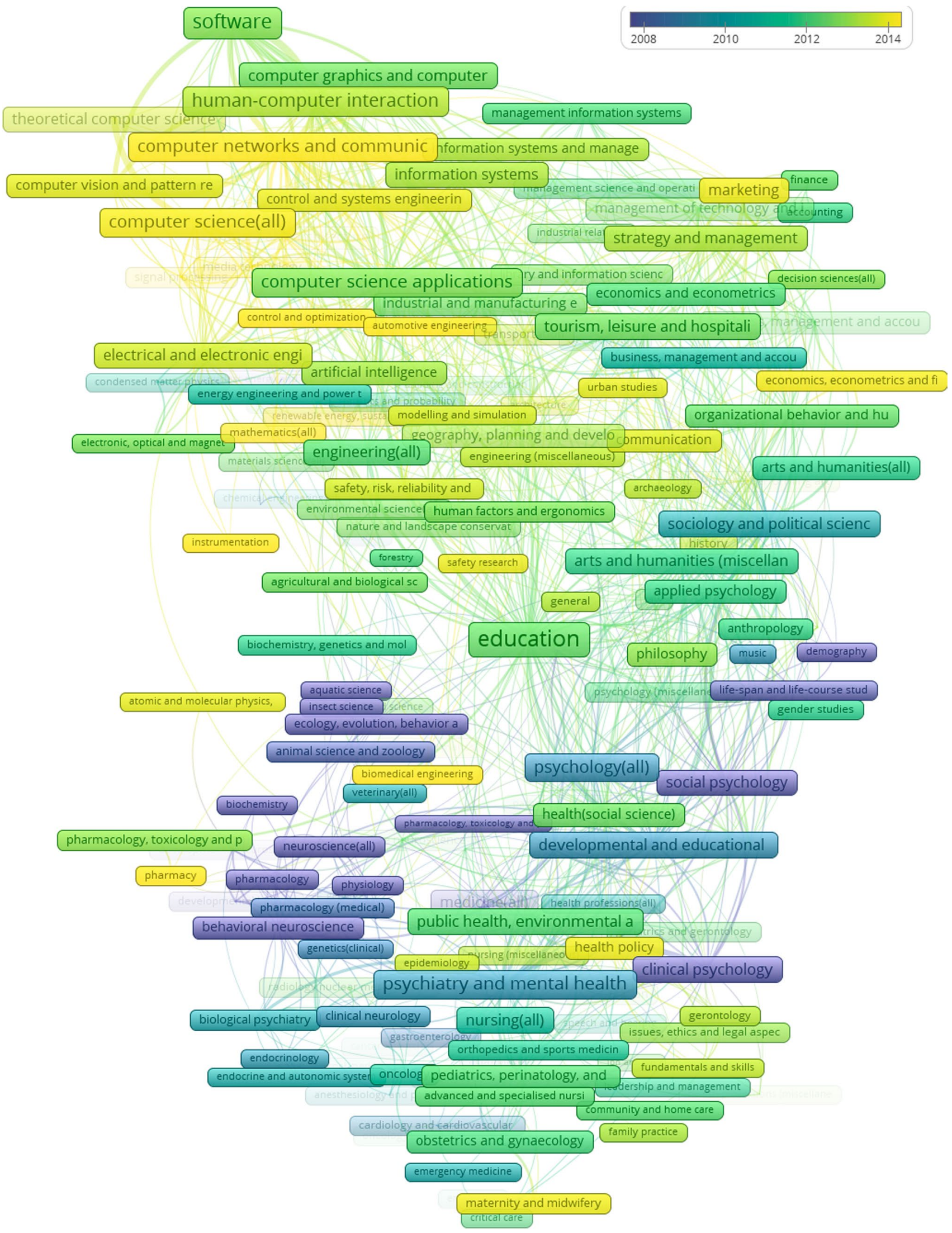


4Fig. 8 The average publication year of the experience publications in the largest experience research fields. Yellow fields are the youngest, purple ones the oldest. Font size $=$ volume of experience publications. Links $=$ at least 50 experience publications in joint publication venues of the research fields

psychological concept rather than a property of technology. We hope that larger groups of experience researchers will follow the Positive Psychology movement and pay attention to the influence of technology in improving human wellbeing.

We still see $\mathrm{HCI}$ as well positioned on the map of experience research, since $H C I$ is multidisciplinary by origin and open to move to new areas needing $H C I$ knowledge. The diffusion of digital systems in all areas of human life will lead to experience researchers from different disciplines turn to $H C I$ research in order to study technologymediated experiences. Therefore, if $\mathrm{HCI}$ publishes high quality experience research, many disciplines will be delighted to utilize it. HCI may become a hub of experience research and even an integrator of experience research knowledge across disciplines.

\section{Limitations}

As with any research profiling study, there are some limitations with this study: an obvious limitation is that not all experience publications are indexed by Scopus. However, Scopus search provided more publications than the same search in Web of Science, and the number of resulting publications, 51,901, was at the upper limit of what the analysis tools and human data cleaners could handle. Even a wider analysis of experience publications could be done once the tools and computers become more powerful and can clean the data more effectively.

The second limitation is that we had to focus the search on author keywords due to the high number of publications $(1.8 \mathrm{M})$ containing the rather general term 'experience' in the title, abstract or Scopus keywords. Not all experience publications include 'experience' or 'experiential' in author keywords, and in some publication venues, there are no author keywords at all. Therefore, some important experience publications are missing from our data set.

Finally, each publication venue is categorized under many research fields in Scopus, which makes it impossible to pinpoint the primary research field for a publication. This has an influence on the disciplinary analyses depicted in Tables 1, 4, 10 and 11, and Figs. 3, 7, 8 and 9, which should be treated as indicative results.

\section{Conclusions}

While human experiences have been studied since Aristotle's times, there is no consensual scientific understanding of the concept of experience. Various disciplines address it from different perspectives and for different purposes, thus we need to understand experience as a multi-disciplinary concept. Since there was no visibility to experience research across disciplines, we conducted a large-scale research profiling study with 51,901 publications in Scopus database where author keywords include 'experience' or 'experiential'. The present study is one of the largest research profiling studies we have seen so far, and we expect to see more large-scale studies profiling disciplines as the capacity of computers and analysis tools increases. This is the first study to reveal the research fields, hubs and authors studying experiences, as well as the strongest links between the fields.

Our study shows the rapidly growing number of publications in this area, which indicates an increasing scholarly interest in experience research. Our data set covers 326 out of 334 ASJC research fields in Scopus, showing that experience is a highly multidisciplinary research topic. Education is the most prolific experience research field, Software the second, and $H C I$ the third. $H C I$ and $\mathrm{UX}$ research in specific have thus an important role in experience research, although the UX works do not easily collect as many citations as the much larger subject area classes of Psychology and Medicine. As digitalization proceeds to new fields, we expect citations from other fields to UX research grow. Thus, $\mathrm{HCI}$ has potential to become an integrator of multi-disciplinary experience research.

The findings of our research profiling can help the UX research community to understand the breadth of experience research and advance knowledge of experiences by examining the works in the neighboring research fields as well as the most cited experience literature. The maps of disciplinary connections (Figs. 7, 8, 9) help researchers to describe their research field on the map of experience research, and they provide useful material for educators to introduce the different perspectives to experience research to students. This review also helps to identify potential collaborators for multi-disciplinary experience research projects. For example, designing for psychological well-being and eudaimonia, or supporting learning and creativity requires multi-faceted understanding of experiences and multi-disciplinary approaches to experience research. Theoretical and methodological aids from other experience research fields can help enable meaningful, valuable, and delightful experiences, as well as address the grand challenges such as behaviour change needed to tackle climate change, designing human-centred future of work with intelligent systems, providing engaging online education, or supporting the 


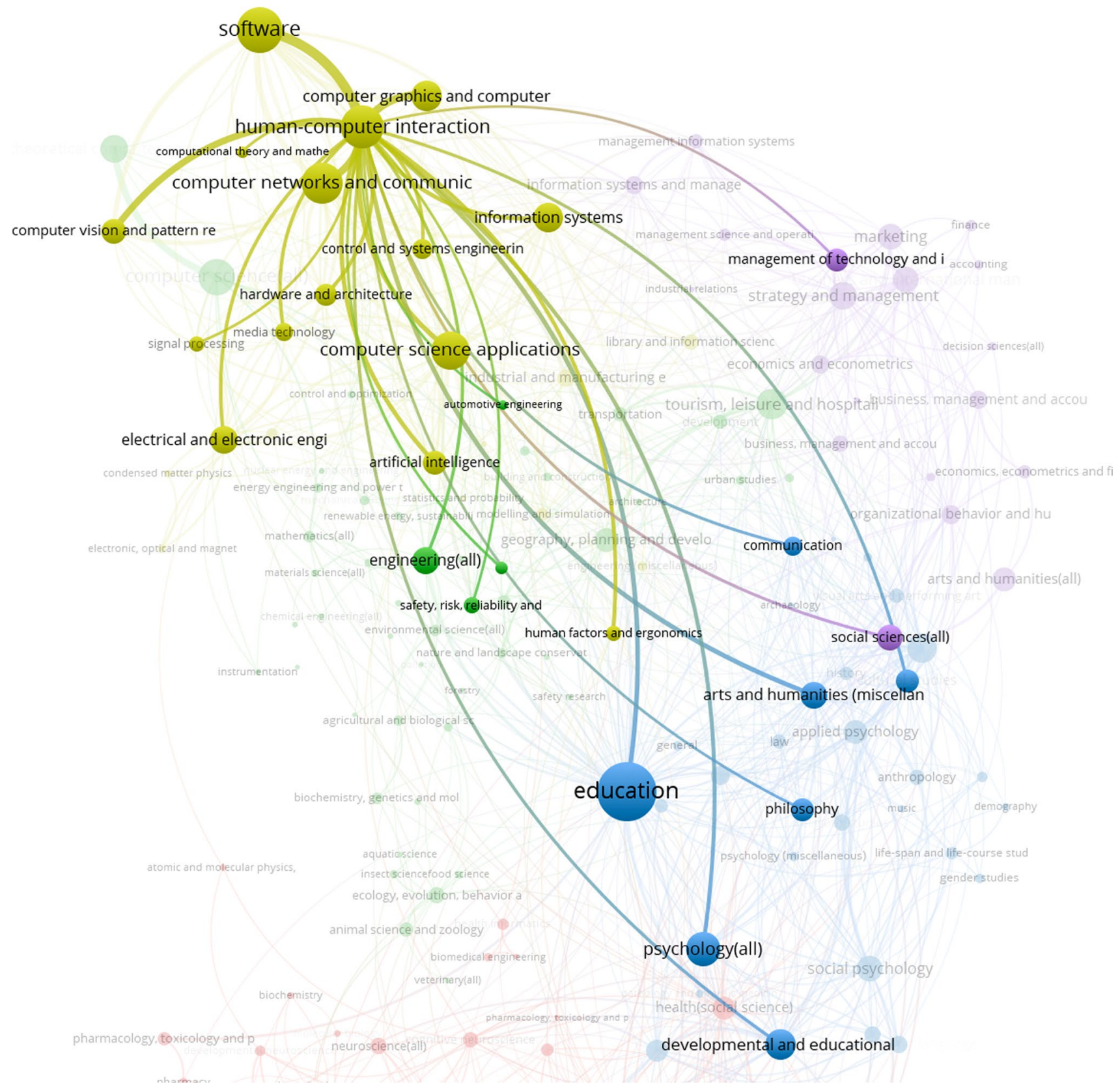

Fig. 9 The links between HCI and other fields based on the joint publication venues

aging population to live a good life. Therefore, we point UX researchers to new areas of study across the experience research fields, although the specific interests and needs will differ. Some may benefit from the models and measures of customer, brand, or lived experience, or the popular methodologies of Naturalistic Inquiry or qualitative research approaches. Some others could get inspiration from Prospect Theory, Social Cognitive Theory and Self-Determination Theory, which appear in Table 9 as the top cited theories in our set of experience publications. Phenomenology shows in our analysis as the highest cited philosophical grounding for experience research, which is useful to acknowledge when studying and teaching user experience.

This research profiling study can be seen as a starting point for a series of studies in establishing a more coherent experience research community. While we have mapped the landscape of experience research, future research is needed to further clarify the topics studied across the experience research fields. More specific literature reviews should be conducted in order to clarify the theories, definitions, methods and measures of experience used in the different fields, which will guide the researchers towards understanding 
experience as a multidisciplinary concept. While studying foreign research fields may be challenging at first, learning from other disciplines would accelerate the development of many experience research fields. We hope the present article helps experience researchers to identify relevant disciplines and scholars in experience research, and to begin co-developing influential concepts, theories, and tools to support experience research across the disciplines. Based on the high cross-disciplinary interest in a new Experience Research Society, ${ }^{3}$ we see high potential in continuing this work towards a more integrated future for the important and quickly growing field of experience research.

Acknowledgements We thank the board of Aalto Experience Platform for the useful comments in the different phases of this study.

Funding Open access funding provided by Aalto University. This work was partly supported by the Academy of Finland. This university profiling funding is for supporting cross-fertilization between the disciplines studying human experiences.

Availability of data and material Supplemental data and material for this article can be accessed online via the VOSviewer service. https://app.vosviewer.com/?map=https://users.aalto.fi/ bragge/exper iencemaps/ASJCLow212mapfile.txt\&network=https://users.aalto.fi/ bragge/experiencemaps/ASJCLow212networkfile.txt.

\section{Declarations}

Conflict of interest On behalf of all authors, the corresponding author states that there is no conflict of interest.

Open Access This article is licensed under a Creative Commons Attribution 4.0 International License, which permits use, sharing, adaptation, distribution and reproduction in any medium or format, as long as you give appropriate credit to the original author(s) and the source, provide a link to the Creative Commons licence, and indicate if changes were made. The images or other third party material in this article are included in the article's Creative Commons licence, unless indicated otherwise in a credit line to the material. If material is not included in the article's Creative Commons licence and your intended use is not permitted by statutory regulation or exceeds the permitted use, you will need to obtain permission directly from the copyright holder. To view a copy of this licence, visit http://creativecommons.org/licenses/by/4.0/.

\section{References}

1. Bandura A (1997) Self-efficacy: The exercise of control. Freeman, New York, $604 \mathrm{p}$

2. Bandura A (2002) Social cognitive theory in cultural context. Appl Psychol 51(2):269-290

3. Bannon L (1991) From human factors to human actors: the role of psychology and human-computer interaction studies in systems design. In: Greenbaum J, Kyng M (eds) Design at work:

\footnotetext{
${ }^{3} \mathrm{http} / / /$ ExperienceResearchSociety.org
}

cooperative design of computer systems. Lawrence Erlbaum Associates, Hillsdale, pp 25-44

4. Bargas-Avila JA, Hornbæk K (2011, May). Old wine in new bottles or novel challenges: a critical analysis of empirical studies of user experience. In: Proceedings of the SIGCHI conference on human factors in computing systems, pp 2689-2698

5. Bødker S (2006, October) When second wave HCI meets third wave challenges. In: Proceedings of the 4 th Nordic conference on human-computer interaction: changing roles, pp 1-8

6. Bragge J, Korhonen P, Wallenius H, Wallenius J (2012) Scholarly communities of research in multiple criteria decision making: a bibliometric research profiling study. Int J Inf Technol Decis Mak 11(2):401-426

7. Brakus JJ, Schmitt BH, Zarantonello L (2009) Brand experience: what is it? How is it measured? Does it affect loyalty? J Mark 73(3):52-68

8. Carlson R (1997) Experienced cognition. Lawrence Erlbaum Associates

9. Chen C (2017) Science mapping: a systematic review of the literature. J. Data Inf Sci 2(2):1-40

10. Cobo MJ, Lopez-Herrera AG, Herrera-Viedma E, Herrera F (2011) Science mapping software tools: review, analysis and cooperative study among tools. J Am Soc Inform Sci Technol 62(7):1382-1402

11. Csikszentmihalyi M (1990) Flow. The psychology of optimal experience. HarperPerennial, New York

12. Delen D, Crossland MD (2008) Seeding the survey and analysis of research literature with text mining. Expert Syst Appl 34(3): 1707-1720

13. Dewey J (1963 reprint) Experience and education. Macmillian, New York

14. Dewey J (1980 reprint) Art as Experience. Perigee, New York

15. Durndell A, Haag Z (2002) Computer self efficacy, computer anxiety, attitudes towards the internet and reported experience with the internet, by gender, in an east European sample. Comput Hum Behav 18(5):521-535

16. Forlizzi J, Ford S (2000) The building blocks of experience: an early framework for interaction designers. In: Proceedings of the 3rd conference on Designing interactive systems: processes, practices, methods, and techniques, pp 419-423

17. Fullerton GS (1894) The psychological standpoint. Psychol Rev $1(2): 113-133$

18. Glaser BG, Strauss AL (1967) The discovery of grounded theory: strategies of qualitative research. Aldine, Chicago

19. Gómez-Corona C, Valentin D (2019) An experiential culture: a review on user, product, drinking and eating experiences in consumer research. Food Res Int 115:328-337

20. Harzing A-W (2015) Health warning: Might contain multiple personalities. The Problem of Homonyms in Thomson Reuters Essential Science Indicators. Scientometrics 105(3):2259-2270

21. Harzing A-W (2016) Health warning: might contain multiple personalities, Harzing.com, blog writing May 25, 2016, retrieved from: https://harzing.com/blog/2016/05/health-warning-mightcontain-multiple-personalities

22. Harzing A-W, Alakangas S (2016) Google scholar, scopus and the web of science: a longitudinal and cross-disciplinary comparison. Scientometrics 106(2):787-804

23. Hassenzahl M, Tractinsky N (2006) User experience-a research agenda. Behav Inf Technol 25(2):91-97

24. Ives CD, Giusti M, Fischer J, Abson DJ, Klaniecki K, Dorninger C, Raymond CM (2017) Human-nature connection: a multidisciplinary review. Currt Opin Environ Sustain 26:106-113

25. Johnson T, Dasu T (2003) Data quality and data cleaning - an overview. In: Proceedings of the 2003 ACM SIGMOD international conference on management of data. ACM Press, San Diego, pp 681-681 
26. Jordan P (2000) Designing pleasurable products. An introduction to the new human factors. Taylor \& Francis, London

27. Kiili K (2005) Digital game-based learning: towards an experiential gaming model. Internet Higher Educ 8(1):13-24

28. Kolb DA (1984) Experiential learning: experience as the source of learning and development. Prentice Hall, Upper Sadle River

29. Larson R, Csikszentmihalyi M (1983) The experience sampling method. New Dir Methodol Soc Behav Sci 15:41-56

30. Law ELC, Roto V, Hassenzahl M, Vermeeren APOS, Kort J (2009) Understanding, scoping and defining user experience: A survey approach. Paper presented at the conference on human factors in computing systems-proceedings, pp 719-728

31. Lee CS, Ma L (2012) News sharing in social media: the effect of gratifications and prior experience. Comput Hum Behav 28(2):331-339

32. Lincoln Y, Guba E (1985) Naturalistic inquiry. Sage Publications, Newbury Park

33. Merleau-Ponty M (1962) Phenomenology of perception. Routledge, London

34. Norman D, Miller J, Henderson A (1995, May) What you see, some of what's in the future, and how we go about doing it: HI at Apple Computer. In: Conference companion on Human factors in computing systems. ACM, p 155

35. Pandey N, Patwardhan AA, Rao S (2019) Four decades of new product development research: an integrative review. Int J Prod Dev 23(1):1-14

36. Parasuraman A, Zeithaml VA, Berry LL (1985) A conceptual model of service quality and its implications for future research. J Mark 49(4):41-50

37. Patton MQ (2002) Qualitative research \& evaluation methods: integrating theory and practice. Sage Publications, Newbury Park

38. Pine J, Gilmore JH (1998) Welcome to the experience economy. Harv Bus Rev 76(4):97-106

39. Pine BJ, Gilmore JH (1999) The experience economy: work is theatre \& everyday business a stage. Harvard Business School Press, Boston, $254 \mathrm{p}$
40. Porter AL, Cunningham SW (2005) Tech mining: exploiting new technologies for competitive advantage. Wiley, Hoboken

41. Porter AL, Kongthon A, Lu R (2002) Research profiling: improving the literature review. Scientometrics 53(3):351-370

42. Rafols I, Porter AL, Leydesdorff L (2010) Science overlay maps: a new tool for research policy and library management. J Am Soc Inform Sci Technol 61(9):1871-1887

43. Reber R (2008) Art in its experience: can empirical psychology help assess artistic value? Leonardo 41(4):367-372

44. Rebula de Oliveira U, Souza Espindola L, Rocha da Silva I, Nostorio da Silva I, Martins Rocha H (2018) A systematic literature review on green supply chain management: research implications and future perspectives. J Clean Prod 187:537-561

45. Seaborn K, Fels DI (2015) Gamification in theory and action: a survey. Int J Hum Comput Stud 74:14-31

46. Somervuori O (2014) Profiling behavioral pricing research in marketing. J Prod Brand Manag 23(6):462-474

47. Sunikka A, Bragge J (2012) Applying text-mining to profile personalization and customization research-who, what and where? Expert Syst Appl 39(11):10049-10058

48. Tiger L (1992) The pursuit of pleasure. Little, Brown \& Co., Boston

49. van Eck NJ, Waltman L (2010) Software survey: VOSviewer, a computer program for bibliometric mapping. Scientometrics 84:523-538

50. Verhoef PC, Lemon KN, Parasuraman A, Roggeveen A, Tsiros M, Schlesinger LA (2009) Customer experience creation: determinants, dynamics and management strategies. J Retail 85(1):31-41

Publisher's Note Springer Nature remains neutral with regard to jurisdictional claims in published maps and institutional affiliations. 